\title{
DECADENCIA DEL VIÑEDO \\ $Y$ CRISIS POBLACIONAL \\ EN LA MALAGA DE FINALES \\ DEL SIGLO XIX *
}

\section{CARMELO PELLEJERO MARTINEZ \\ Universidad de Málaga}

\section{LA DECADENCIA DEL VIÑEDO MALAGUEÑO EN LA SEGUNDA MITAD DEL SIGLO XIX}

\subsection{Evolución de la superficie}

El viñedo es uno de los cultivos más tradicionalmente importantes de la agricultura malagueña. Las cepas han formado parte del paisaje agrario de la provincia de Málaga desde tiempo inmemorial, quedándonos constancia de que ya en la época romana y, sobre todo, durante la floreciente dominación musulmana, las pasas y los vinos malagueños eran productos muy apreciados y gozaban de gran renombre a nivel mundial '.

Tras los incrementos de superficie experimentados en los siglos XVI y xvil, en la segunda mitad del siglo xviII, y a consecuencia de una muy importante demanda exterior, el viñedo malagueño conoció una fase de clara expansión. Esta etapa expansiva se vio frenada en los últimos años del siglo xvil y primeros del xIx. Una serie de factores negativos, como el bloqueo continental, la ocupación francesa, la insurrección de las colonias americanas, contribuyeron a provocar una fuerte crisis coyuntural para el comercio vitivinícola malagueño.

Acabadas las guerras napoleónicas se fueron paulatinamente recuperando los mercados extranjeros. Además, con el siglo xix llegó la libertad de cultivos que permitió a la viña poder bajar a las tierras de sembradura. Todo ello contribuyó a que la superficie de viñedos creciera durante prácticamente los dos primeros tercios del siglo pasado. La expansión sufrió un serio revés a partir de 1878, año en el que la filoxera invadió Málaga. Antes de que finalizase la centuria, todo el viñedo existente al inicio de la invasión filoxérica había desaparecido.

* Acctsit en el Premio Ramón Carande de 1987.

' Guillén Robles (1874), p. 215. 
$\mathrm{Al}$ analizar el cuadro 1 podemos comprobar cómo los efectos de la plaga fueron devastadores para el campo malagueño. Sin embargo, creo que, independientemente del terrible poder destructor del insecto, hubo una serie de factores que coadyuvaron a agravar la crisis del viñedo. Más adelante los explicaremos detenidamente. Ahora, y para facilitar una mejor comprensión de la trayectoria seguida por la superficie de viñas, me limitaré a señalarlos.

Cuando la filoxera da por vez primera señales de su existencia, el sector vitivinícola provincial venía ya atravesando por serias dificultades, tanto de carácter comercial como de elaboración de los productos. El vino y la pasa de Málaga vivían momentos especialmente difíciles en los mercados extranjeros. Por otro lado, la pequeña propiedad estaba generalizada en la mayor parte de las tierras de viñedo. Las viñas, por lo tanto, se encontraban en manos de pequeños propietarios que, generalmente, disponían de recursos muy escasos. Esta falta de medios desempeñaría un papel decisivo en el fracaso de la replantación. La excesiva compartimentación de la tierra, la falta de recursos, la grave situación coyuntural por la que atravesaban los productos de la vid, contribuyeron, sin la menor duda, a que la virulencia de la plaga alcanzara en la provincia de Málaga cotas verdaderamente dramáticas.

\section{CUADRO 1}

Evolución de la superficie de viñedos. Provincia de Málaga (Hectáreas)

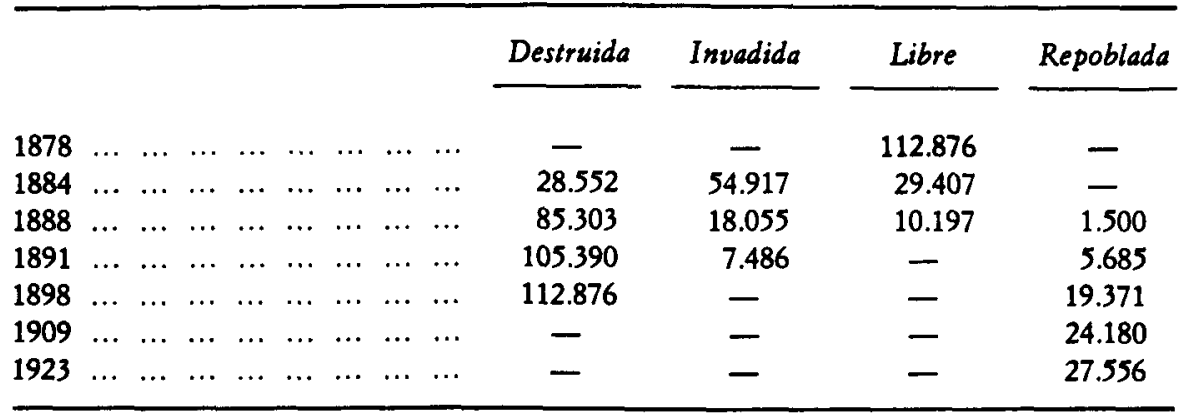

FuENTES: Servicios Agronómicos, Estadísticas de producción y cultivo, 1888-1900, legajo 259; Carnero (1980), p. 126; La Crisis Agrícola y Pecuaria (1887-1889), tomo V, p. 727; Comisión Central de Evaluación y Catastro (1898); Ministerio de Fomento, Dirección General de Agricultura, Industria y Comercio (1911), p. 152; Ministerio de Fomento, Dirección General de Agricultura y Montes (1923), p. 374. 
Los primeros síntomas de la plaga se detectaron en Moclinejo, pueblo situado a unos veinte kilómetros de la capital, y más concretamente en el lagar de la Indiana. En 1877 se había producido en dicho lagar la muerte de cuatro o cinco cepas, fenómeno que el propietario, Eugenio Molina, atribuyó a la sequía de años anteriores. Pero cuando en el verano de 1878 el número de cepas muertas ascendía a 40 ó 50 , decidió dar parte del hecho. Quería que se examinasen sus vides y que se le informase acerca de la enfermedad que padecían.

La Sociedad Malagueña de Ciencias Físicas y Naturales fue la encargada de estudiar el caso. El día 10 de julio declaraba de manera oficial que el insecto examinado era la filoxera vastatrix. Hecha esta declaración, la Junta Provincial de Agricultura, Industria y Comercio reunió a todas las corporaciones de Málaga, tanto oficiales como oficiosas. Con vocales representantes de todas ellas constituyó una comisión interina de defensa contra la filoxera $^{2}$.

Entre otros acuerdos, la comisión decidió dirigirse a la Diputación Provincial para que facilitase, de manera inmediata, fondos con los que poder iniciar los trabajos de extinción. Recurrió también a los capitalistas de la ciudad, a los que instó a realizar préstamos para así poder llevar a cabo la extinción total del foco filoxérico. El resultado de tales gestiones no pudo ser más negativo. La Diputación contestó que carecía de fondos y que sólo podría conceder las 2.500 pesetas que había consignadas en el presupuesto para calamidades públicas. Los capitalistas, por su parte, estarian en gran medida dispuestos a prestar las cantidades necesarias siempre y cuando la Diputación garantizase el pago de una manera satisfactoria. Como la Diputación no se prestó a tales exigencias, fracasaron todas las operaciones de crédito y todos los planes de la comisión interina. Mientras tanto, el 30 de julio se aprobaba la Ley contra la filoxera.

El profesor Mariano de la Paz Graells, comisionado por el Gobierno para estudiar la filoxera sobre el terreno, se personó en Málaga el día 6 de agosto y lo primero que hizo fue tener una junta preparatoria a la que asistieron, entre otros, el Gobernador, el Presidente de la Diputación y el Alcalde. En dicha reunión se trató de indagar la posible procedencia de la plaga. Se averiguó que el dueño de la finca filoxerada había realizado por los años 1874 y 1875 una plantación de especies de adorno procedentes de países extranjeros. Se decidió que éste era el origen de la plaga y se sospechó que la misma se hubiera difundido ya por los alrededores de la viña enferma.

El día 9 Graells se trasladó a la finca donde había hecho su aparición

${ }^{2}$ Esta información y gran parte de la que se expone a continuación se basa en la documentación Sobre enfermedades de la vid. 
la filoxera. Tras estudiar sobre el terreno la zona afectada, se comprobó que la plaga se encontraba muy extendida. Había 11 propiedades infectadas, algunas de ellas en grandes proporciones. Se hallaban invadidas 31 hectáreas y urgía arrancar más de cien mil cepas ${ }^{3}$. Como el insecto se estaba dispersando ya en su forma alada, se omitió el procedimiento prescrito en el artículo $9 .^{\circ}$ de la Ley contra la filoxera, es decir, el arranque y posterior quema. Se decidió establecer un foso de incomunicación, quemar la cabeza de la cepa, regar el suelo con agua amoniacal y el mástil de cada cepa con coaltar y cubrir después todo el suelo con cal de depuración del gas. Esta fue la primera forma de defensa contra la filoxera ${ }^{4}$.

Constituida la Comisión Provincial de Defensa contra la Filoxera, y consciente de la urgente necesidad de disponer de recursos económicos para luchar contra la plaga, realizó una serie de solicitudes a la Diputación Provincial y al Ayuntamiento. Este primer intento no dio el resultado apetecido, ya que apenas se consiguieron las 2.500 pesetas que podía donar la Diputación. En vista de la delicada situación, y en base a lo estipulado en el artículo 13 de la Ley contra la filoxera, la Comisión decidió acudir al Gobierno, pero tampoco obtuvo un resultado positivo.

Además de las serias dificultades existentes para recaudar fondos, la Comisión se enfrentaba con otra serie de problemas que paralizaban los posibles mecanismos de defensa contra la filoxera. Entre gran parte del campesinado existía la creencia de que el estado ruinoso en que se encontraban sus viñas no era debido a otra cosa que a la sequía que venía azotando la provincia desde hacía cuatro o cinco años. Consideraban a la filoxera como un efecto y no como la causa del estado anémico que padecían sus viñas. Por esta razón los propietarios de las vides atacadas hicieron muy poco para defenderse del insecto pensando que con la llegada de las lluvias se acabaría el problema ${ }^{5}$.

Por otro lado, la depreciación que desde hacía varios años venía sufriendo la pasa fue otro factor que contribuyó a que, en un primer momento, se tuviera una actitud hasta cierto punto indiferente frente a la filoxera. En la provincia de Málaga había dos ámbitos geográficos donde la pasa se producía de una manera más importante. Uno de ellos era el terreno llano, vegas u hoyas, destacando la Hoya de Málaga, en donde las tierras eran buenas y los propietarios, principalmente pertenecientes a la burguesía de la ciudad, disponían de capital y producían mediante trabajo asalariado ${ }^{6}$.

La otra región era la montañosa. En ella el suelo era generalmente árido

Sobre enfermedades de la vid, legajo 20.

- La Crisis Agricola y Pecuaria (1887-1889), tomo V, p. 724.

3 Sobre enfermedades de la vid, legajo 20.

- Guisado (1983). 
y el sistema de propiedad imperante era el minifundio. El viticultor de los montes, propietario y jornalero a la vez, trabajaba en la costa, las vegas y en otras zonas de la provincia. En sus ratos de ocio cultivaba sus viñas y vendía los productos a bajos precios, gracias a las aportaciones que obtenía por sus actividades como trabajador temporero. Con ello obtenía un escaso beneficio, pero suficiente para remunerar su trabajo en unos días que de otro modo perdería. Además, con su actitud ejercía una gran competencia a los agricultores de las vegas ${ }^{7}$.

Cuando aparece la filoxera la pasa malagueña estaba atravesando por serias dificultades en los mercados internacionales. Se vendía menos y a menor precio. Esta depreciación de la pasa hacía de todo punto imposible a los viticultores de los montes proseguir con el cultivo de la vid. La irrupción de la filoxera sólo sirvió, pues, para que se reafirmaran en su decisión de abandonar el cultivo. Los agricultores de la Hoya vieron en la filoxera la posibilidad de acabar con la competencia ejercida por los viticultores de la montaña. Por esa razón se desentendieron del problema al comprobar que la plaga se desencadenaba en los montes y que, en un primer momento, sus efectos destructores se limitaban a dicha zona ${ }^{8}$.

$\mathrm{La}$ escasez de recursos económicos para luchar contra la filoxera, la actitud hasta cierto punto indiferente que ciertos sectores del campo malagueño adoptaron frente a la plaga, e incluso las presiones y amenazas que, tras la marcha del profesor Graells, tuvieron que padecer sus auxiliares que quedaron en Málaga, fueron factores que coadyuvaron a que tuviera que suspenderse la campaña. En los años siguientes se adoptaron diversas medidas defensivas para evitar la expansión de la plaga, pero no se consiguió ningún resultado eficaz.

La filoxera avanzó de manera rápida y constante por toda la Axarquía y vega litoral de Vélez. Más tarde, y algo más lentamente, invadió la vega del río Guadalhorce. Esta diferencia de velocidad en la expansión del insecto obedeció a que en la zona de la vega, a diferencia de la Axarquía en donde los suelos eran áridos y pedregosos, los terrenos ricos de naturaleza silíceoarcillosa, reposando sobre subsuelos arcillosos que permitían conservar mejor las humedades invernales, nutrían vides más vigoroșas que tardaron más tiempo en sucumbir a los ataques de la plaga ${ }^{9}$.

Antes de que la filoxera hubiera hecho su aparición, las viñas ocupaban una extensión de 112.876 hectáreas. Aunque las cepas se extendían por toda la provincia malagueña, predominaban especialmente en las comarcas de la

\footnotetext{
7 Sobre entermedades de la vid, legajo 20.

- Sobre enfermedades de la vid, legajo 20.

- Ministerio de Fomento, Dirección General de Agricultura, Industria y Comercio (1911), p. 148.
} 
Axarquía y del Litoral. En estas dos regiones se concentraba el 70,3 por 100 de todo el viñedo provincial.

\section{CUADRO 2}

Superficie de viñedos existente en Málaga antes de la filoxera

\begin{tabular}{|c|c|}
\hline Comarcas & Hectáreas \\
\hline 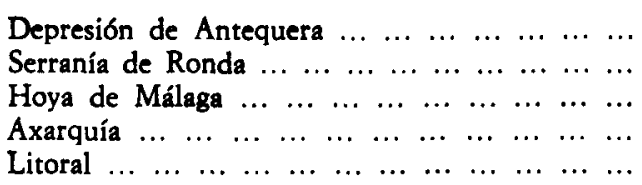 & $\begin{array}{r}6.145 \\
13.494 \\
13.889 \\
33.506 \\
45.842\end{array}$ \\
\hline TOTAL $\operatorname{PROVINCIAL} \ldots \ldots \ldots$ & 112.876 \\
\hline
\end{tabular}

FuENTE: Elaboración propia a partir de Servicios Agronómicos, Estadísticas de producción y cultivo, 1888-1900, legajo 259.

Apenas seis años después de que se declarara de manera oficial la presencia del insecto en nuestra provincia, la plaga había destruido 28.552 hectáreas. Esto supuso la completa desaparición del cultivo en 14 municipios de la provincia, concretamente en Algarrobo, Almáchar, Benagalbón, Benamargosa, Banamocarra, Borge, Comares, Cútar, Iznate, Macharaviaya, Moclinejo, Olías, Totalán y Vélez ${ }^{10}$. Estos pueblos estaban situados cerca del primer foco filoxerado y en dirección este. Tres de ellos -Algarrobo, Benagalbón y Vélez- eran costeros, mientras que el resto pertenecían a la montañosa comarca de la Axarquía.

Aparte de las hectáreas de viñas completamente arrasadas por la filoxera, existían otras 54.917 que se encontraban infectadas por el insecto. Esto ocurría en aquellos municipios de la Axarquía donde el viñedo no había sido totalmente destruido, en parte de la Hoya de Málaga y en la mayoría de los pueblos del Litoral. La filoxera inició, pues, su expansión en dirección este y una vez invadida la parte oriental de la provincia se dirigió hacia occidente. En este año de 1884 la filoxera no había logrado entrar ni en la Depresión de Antequera ni en la Serranía de Ronda, es decir, en las zonas norte y occidental de la provincia. Tampoco habia logrado invadir los viñedos de

${ }^{10}$ Carnero (1980), p. 126. 
Coín y Cártama, pueblos de la Hoya, y de Estepona y Manilva, municipios costeros más occidentales.

\section{CUADRO 3 \\ Superficic de viñedos existente en Málaga en 1884 (Hectáreas)}

\begin{tabular}{|c|c|c|c|}
\hline Comarcas & Destruida & Invadida & Libre \\
\hline 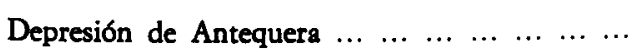 & - & - & 6.145 \\
\hline Serranía de Ronda $\begin{array}{ccccccccc} & \ldots & \ldots & \ldots & \ldots & \ldots & \ldots & \ldots & \ldots\end{array}$ & - & - & 13.494 \\
\hline 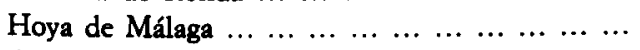 & - & 6.625 & 7.264 \\
\hline $\begin{array}{llllllllllll}\text { Axarquía } & \ldots & \ldots & \ldots & \ldots & \ldots & \ldots & \ldots & \ldots & \ldots & \ldots & \ldots\end{array}$ & 14.352 & 21.424 & 39 \\
\hline $\begin{array}{lllllllllllllll}\text { Litoral } & \ldots & \ldots & \ldots & \ldots & \ldots & \ldots & \ldots & \ldots & \ldots & \ldots & \ldots & \ldots\end{array}$ & 14.200 & 26.868 & 2.465 \\
\hline TOtal PROVINCIAL $\ldots \ldots \ldots \ldots$ & 28.552 & 54.917 & 29.407 \\
\hline
\end{tabular}

FUENTES: Elaboración propia a partir de Servicios Agronómicos, Estadísticas de producción y cultivo, 1888-1900, legajo 259; Carnero (1980), p. 126.

\section{CUADRO 4}

Superficie de viñedos existente en Málaga en 1891 (Hectáreas)

\begin{tabular}{|c|c|c|c|c|}
\hline Comarcas & Destruida & Invadida & Libre & Repoblada \\
\hline Depresión de Antequera ... ... ... & 5.890 & 255 & - & - \\
\hline Serranía de Ronda $\ldots \ldots \ldots \ldots \ldots$ & 7.569 & 5.925 & - & 124 \\
\hline 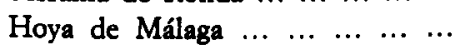 & 14.030 & - & - & 1.048 \\
\hline $\begin{array}{llllllll}\text { Axarquía } & \ldots & \ldots & \ldots & \ldots & \ldots & \ldots & \ldots\end{array}$ & 35.815 & - & - & 1.404 \\
\hline $\begin{array}{llllllllll}\text { Litoral } & \ldots & \ldots & \ldots & \ldots & \ldots & \ldots & \ldots & \ldots\end{array}$ & 42.086 & 1.306 & - & 3.109 \\
\hline TOtAL pRovincial $\ldots \ldots \ldots$ & 105.390 & 7.486 & - & 5.685 \\
\hline
\end{tabular}

FUENTE: Elaboración propia a partir de Servicios Agronómicos, Estadisticas de producción y cultivo, 1888-1900, legajo 259. 
MAPA 1

Superficie de viñedos. Año 1884

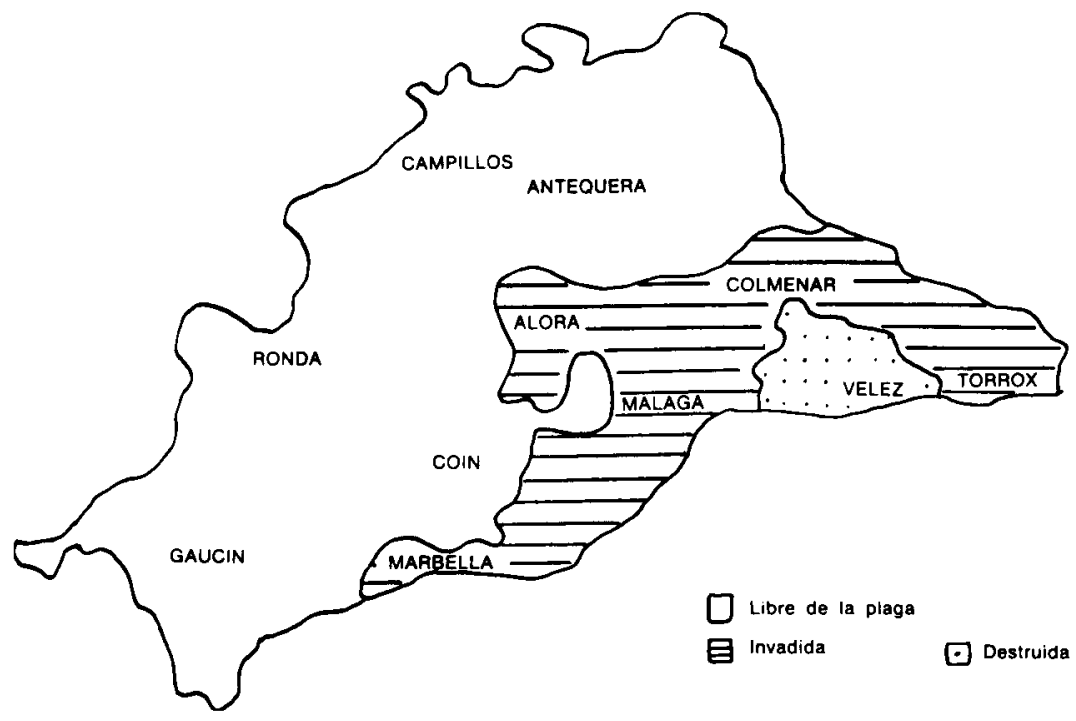

Fuentes: Elaboración propia a partir de Servicios Agronómicos, Estadísticas de producción y cultivo, 1888-1900, legajo 259; Carnero (1980), p. 126.

En 1891, sólo trece años después de que fuera detectada la filoxera por primera vez, la plaga había afectado prácticamente a toda la provincia. De las 112.876 hectáreas existentes al inicio de la invasión, había destruido 105.390 y contaminado las restantes. Las únicas viñas que, estando contaminadas, no habían sido todavía destruidas estaban localizadas en algunos municipios de la Serranía de Ronda y en Estepona y Manilva, pueblos sitos en el extremo más occidental del litoral malagueño.

En los siguientes años la filoxera culminó su acción destruyendo las escasas cepas que todavía no habían sucumbido a sus ataques. Entre 1895 y 1900 fue difícil encontrar en Málaga algunos pies reunidos del antiguo viñedo ${ }^{11}$.

"Ministerio de Fomento, Dirección General de Agricultura, Industria y Comercio (1911). 
Es muy probable, por tanto, que las 19.371 hectáreas de viñedos existentes en 1898 fueran superficie replantada.

\section{CUADRO 5}

Superficie de viñedos existente en Málaga en 1898

\begin{tabular}{|c|c|}
\hline Comarcas & Hectäreas \\
\hline 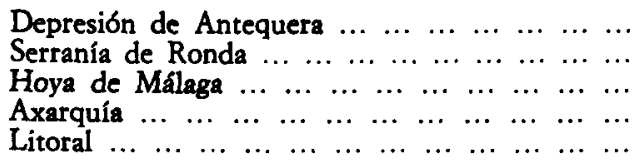 & $\begin{array}{r}252 \\
238 \\
1.962 \\
4.941 \\
11.978\end{array}$ \\
\hline 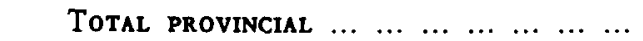 & 19.371 \\
\hline
\end{tabular}

FuENTE: Elaboración propia a partir de Comisión Central de Evaluación y Catastro (1898).

\subsubsection{La replantación.}

En 1898, veinte años después de que comenzara la invasión filoxérica, se habían destruido 112.876 hectáreas de viñas y la cantidad replantada apenas representaba el 17 por 100 del viñedo primitivo. En un primer momento la replantación, además de reducida, no fue homogénea en toda la provincia. En el cuadro 6 puede observarse que a final de siglo se habían producido modificaciones en el viñedo provincial. Hubo tres comarcas - Axarquía, Serranía de Ronda y Depresión de Antequera - que perdieron importancia dentro del sector. Hubo otra, la Hoya, que en líneas generales se mantuvo en el nivel existente al inicio de la invasión, mientras que el Litoral fue la única que aumentó su participación.

¿Por qué en unas comarcas se replantó más que en otras? Para una mejor comprensión de este problema es conveniente analizar todo el proceso repoblador llevado a cabo en Málaga.

Tras irrumpir la plaga se desató una fuerte polémica entre aquellos partidarios de luchar contra ella empleando insecticidas y los que abogaban por la replantación de los viñedos con cepas resistentes. Los primeros se vieron rápidamente defraudados, ya que, tras usar diversos insecticidas, ninguno proporcionó un resultado positivo. El medio de defensa más empleado en la 


\section{CUADRO 6}

Superficie de viñedos

(Porcentaje respecto al total)

\begin{tabular}{|c|c|c|}
\hline Comarcas & $\begin{array}{l}\text { Antes de } \\
\text { invasion }\end{array}$ & 1898 \\
\hline 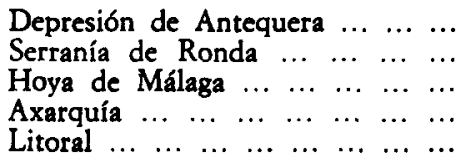 & $\begin{array}{r}5,5 \\
11,9 \\
12,3 \\
29,7 \\
40,6\end{array}$ & $\begin{array}{r}1,3 \\
1,2 \\
10,2 \\
25,5 \\
61,8\end{array}$ \\
\hline
\end{tabular}

FUENTES: Elaboración propia a partir de Servicios Agronómicos, Estadísticas de producción y cultivo, 1888-1900, legajo 259; Comisión Central de Evaluación y Catastro (1898).

provincia de Málaga fue, pues, el que se fundaba en la resistencia de algunas especies de vides.

A Málaga llegaron semillas de diferentes especies y variedades. De todas ellas la Riparia fue la recomendada, tanto por la Sociedad Malagueña de Ciencias Físicas y Naturales como por el ingeniero agrónomo Juan Alvarez Sánchez ${ }^{12}$. El tiempo demostraría que este consejo no era del todo acertado por lo que se refiere al conjunto de la provincia. No tardó en advertirse que la variedad Riparia daba admirables resultados en los terrenos llanos, pero fracasaba estrepitosamente en los montañosos ${ }^{13}$. Esto era debido a una falta de adecuación entre la Riparia y el medio en que se desarrollaba ${ }^{14}$. Las raíces de la citada variedad eran delgadas y de débil poder penetrante. En los montes, con terrenos pedregosos, áridos y poco profundos, las raíces se extendían lateralmente sin ganar en profundidad. Esto provocaba que las plantas injertadas en Riparia crecieran raquíticas y dieran escasa producción.

La Riparia, para fructificar, necesitaba de suelos de aluvión silíceos, ricos en hierro, frescos y bien saneados. Esto sólo ocurría en la zona de la vega de Málaga. Así se explica que sea la Hoya de Málaga la comarca que en un primer momento, 1891, tiene un mayor éxito en la replantación. Allí se formaron magníficos plantíos, productores de mejores y más abundantes uvas que las cosechadas antiguamente en los viñedos indígenas ${ }^{15}$.

\footnotetext{
${ }^{12}$ La Crisis Agricola y Pecuaria (1887-1889), tomo V, pp. 725 y 726, y Lacomba (1980), p. 357.

${ }_{13}$ Pancorbo (1901), p. 30.

14 Salas y Amat (1891).

13 Pancorbo (1901), p. 30.
} 


\section{CUADRO 7}

Porcentaje de superficie replantada respecto a la existente al inicio de la filoxera. Málaga

\begin{tabular}{|c|c|c|}
\hline Comarcas & 1891 & 1898 \\
\hline 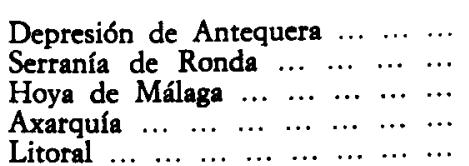 & $\begin{array}{l}0,0 \\
0,9 \\
7,5 \\
4,2 \\
6,8\end{array}$ & $\begin{array}{r}4,1 \\
1,8 \\
14,1 \\
14,7 \\
26,1\end{array}$ \\
\hline
\end{tabular}

FuENTE: Elaboración propia a partir de los cuadros 2,4 y 5 .

El problema de la replantación se había planeado mal desde un principio. Se había elegido un patrón que no se desarrollaba bien en los terrenos montañosos, precisamente donde había plantados una mayor cantidad de viñedos. Se hacía necesario, pues, encontrar patrones de raíces gruesas y perforantes. Merced a los importantes estudios realizados por el ingeniero Salas, se comprobó que existían otras especies que cumplían tales condiciones. Se trataba, en general, de patrones híbridos de diversas especies americanas, entre las que tenía un papel destacado la Rupestris ${ }^{16}$.

Con la nueva variedad de patrones utilizados se consiguió una mayor eficacia en la replantación. El viñedo repoblado pasó de 5.685 hectáreas en 1891 , a 19.371 en 1898 , y 24.180 en 1909 . A medida que fue avanzando el siglo $x x$ el viñedo malagueño fue recuperándose paulatinamente, pero sin conseguir aproximarse a las cotas existentes antes de la invasión. Prueba de ello es que en 1930 la superficie de viñedos existente en Málaga suponía el 29 por 100 de la que había en 1878 .

Dentro de esta tónica general de fracaso repoblador, hubo comarcas, como ya vimos anteriormente, donde se replantó una mayor cantidad de viñas. Nos hubiera gustado haber podido estudiar la evolución de la superficie repoblada por comarcas durante un período dilatado de tiempo, pero la escasa información disponible nos impidió prolongar nuestro análisis más allá del año 1898. Hasta dicho momento, la comarca donde la replantación alcanzó un mayor éxito relativo fue el Litoral, sobre todo la capital de la provincia y los municipios de Vélez y Torrox. ¿Por qué el viñedo tuvo una mejor y más rápida recuperación en dicha comarca y no en otras?

\footnotetext{
16 Jiménez Blanco (1984), p. 638.
} 
La replantación implicaba una inversión muy considerable. Para que los agricultores se decidieran a realizarla era necesario que dispusieran de los fondos pertinentes y que la situación aconsejara aplicar dichos fondos a tal fin y no a otros. En la provincia de Málaga los recursos económicos por esas fechas no eran, en líneas generales, especialmente abundantes. Además, la situación que vivía el sector no era nada halagüeña. Como veremos más adelante, existían graves problemas para colocar los vinos y las pasas malagueñas en los mercados internacionales. La coyuntura, pues, no era la más idónea para que los campesinos malagueños se lanzaran a replantar todo el viñedo primitivo. Ni tenían dinero, ni veían nada claro dedicar sus esfuerzos a un cultivo cuyos productos, en esos años, atravesaban por serias dificultades comerciales.

La repoblación se dio especialmente en aquellas zonas donde los propietarios disfrutaban de un nivel medio de recursos más alto $\mathrm{y}$, además, eran dueños de tierras aptas para el cultivo. Es decir, en aquellos lugares donde, además de haber dinero, la tierra daba buenos rendimientos $\mathrm{y}$, por lo tanto, era factible obtener unos productos que pudieran ser competitivos en los mercados. Estas condiciones se cumplían en la Hoya de Málaga y en el Litoral. En ambas comarcas había propietarios que eran dueños de magníficos plantíos y que disponían de recursos considerables. Ellos podían gastarse su dinero en repoblar las tierras sabiendo que sus frutos serían de buena calidad y que, una vez eliminada la competencia ejercida desde la Axarquía, encontrarían mejores salidas en los mercados.

La Depresión de Antequera y la Serranía de Ronda no fueron nunca zonas realmente viñeras. Sus terrenos no eran especialmente aptos para el cultivo y sus vinos fueron siempre de inferior calidad y destinados exclusivamente a la destilación. El cultivo de la vid fue en todo momento marginal, por lo que se entiende que, ante las graves dificultades por las que atravesaba el sector, los campesinos no tuvieran demasiado interés en la replantación. En la Axarquía, por contra, el viñedo estuvo siempre presente. En dicha comarca, los productos de la vid alcanzaron en todo momento una calidad reconocida. El motivo del atraso en la replantación fue, en este caso, la escasez de recursos monetarios con los que hacer frente a los elevados costes de la operación. No debemos olvidar que en esta comarca la pequeña propiedad era imperante y que los propietarios eran a su vez jornaleros que trabajaban temporalmente en otras zonas de la provincia e incluso de Andalucía.

A pesar, pues, de la repoblación llevada a cabo, lo cierto es que el viñedo malagueño ya no volvió a disfrutar del esplendor de épocas pretéritas. Durante la segunda mitad del siglo xIx la vertiente vitivinícola de 
la economía agraria provincial experimentó un proceso de grave decadencia. Ello fue el resultado de la conjunción en el tiempo de factores tales como la presencia de la filoxera, la escasez de recursos de los viñeros y las dificultads comerciales que sufrieron los productos de la vid. ¿Por qué el vino y la pasa de Málaga, dos productos de tradicional y afamado prestigio internacional, atravesaron por un período crítico a lo largo de la segunda mitad del siglo XIX?

\subsection{El vino malagueño}

Al hablar del vino de la provincia de Málaga no nos estamos refiriendo a una única clase de producto. En Málaga se han conseguido tradicionalmente diversos tipos de vino perfectamente diferenciados, siendo los más característicos los vinos secos, el vino blanco dulce, el vino dulce de color y el moscatel ${ }^{17}$. Todas estas modalidades eran comercializadas en el extranjero. De ellas, el vino denominado Málaga era el que presentaba una mayor demanda exterior. Por su alta graduación, sabor y calidad formaba parte del grupo de vinos generosos. Su delicada elaboración hacía de él un producto caro, demandado mayoritariamente por las clases altas y medias de algunos países que habían alcanzado un cierto desarrollo, especialmente Inglaterra.

En los años cincuenta y sesenta del siglo XIX, el vino malagueño entró en una profunda crisis. Varios factores contribuyeron a ello. Uno fue la aparición del oidium. Esta plaga, detectada en la década de los años cincuenta, atacó especialmente a los viñedos de cepas Pedro Ximen, es decir, aquellas viñas que producían uvas para vino. En cambio no afectó casi nada a las cepas Moscatel que proporcionaban las excelentes pasas de sol malagueñas. Este detalle, unido a la buena aceptación que por esas fechas disfrutaba la pasa malagueña en los mercados internacionales, contribuyó a que en determinadas zonas de la provincia los viñeros fueran sustituyendo de manera progresiva las variedades que proporcionaban uvas para vinificación por aquellas que eran más aptas para obtener uvas para la desecación.

Por otro lado, la demanda de vino malagueño experimentó una notable reducción a partir de mediados de siglo. A este fenómeno contribuyó el cambio experimentado en la preferencia de los consumidores, que pasaron a demandar vinos más ligeros y más secos, y el establecimiento de la escala alcohólica en Inglaterra, así como los fuertes derechos implantados en los Estados Unidos ${ }^{18}$. La alta graduación alcanzada por el vino malagueño obli-

"Información vinicola (1884), legajo 85.

1" La Crisis Agricola y Pecuaria (1887-1889), tomo IV, p. 174 
gaba a tener que pagar elevados aranceles a la entrada en dichas naciones. Ello redundaba en una subida del precio y en no poder competir con otros vinos de menor graduación. Además, con el fin de obtener un producto más barato, algunos vinateros optaron por adulterar los vinos mediante la adición de alcohol. Este hecho no se realizaba exclusivamente en la provincia de Málaga. En Francia se fabricaban inmensas partidas de vino al que denominaban de Málaga. Este fraude alcanzaba tal magnitud que no sólo invadía los naturales mercados de la producción malagueña, sino que se internaba y pugnaba en la propia localidad de Málaga ${ }^{19}$. Todo este fenómeno de falsificación y adulteración de vinos, llevado a cabo en el interior de la provincia, pero también en países extranjeros, provocó un grave desprestigio del producto en los mercados internacionales, lo que evidentemente sólo sirvió para agravar aún más el problema de la escasez de demanda.

Como puede observarse en el gráfico 1, el período 1860-1873 fue crítico para las exportaciones de vino por el puerto de Málaga. En el quinquenio 1866-1870 las salidas se redujeron en un 46 por 100 respecto a las registradas entre 1856 y 1860 . La pérdida del mercado americano desempeñó un papel decisivo en esta recesión de las exportaciones. Por esos años eran casi nulas las exportaciones a Argentina, Perú, Uruguay, Chile, Brasil y México. Los únicos mercados que todavía no se habían perdido eran los de Venezuela y Cuba ${ }^{20}$.

A partir de 1873 se inició una ligera recuperación de las exportaciones, que fue leve hasta 1880 y más efectiva entre este último año y 1886 . Uno de los factores que pudo contribuir a esta reactivación fue el interés que se tomaron ciertos empresarios malagueños por restablecer la calidad y el buen nombre del vino de la tierra, desprestigiado como consecuencia de las falsificaciones ${ }^{21}$. Estos empresarios se preocuparon por ir introduciendo mejoras en la elaboración de los productos, lo que permitió la obtención de vinos de buena calidad y el restablecimiento de la estimación de los mismos en Europa, principalmente en países como Inglaterra, Francia, Alemania y Holanda.

La mejora en la calidad del vino malagueño favoreció probablemente la revitalización de las exportaciones, pero tal recuperación es posible que no fuera tan importante como pueden darnos a entender las cifras de exportación. Debemos tener presente que es muy probable que por esos años, y como consecuencia de le demanda francesa, se incrementaran notablemente las salidas de vinos no malagueños por el puerto malacitano. La aparición

19 Resumen nacional de la sección estadística de la información vinicola (1884), legajo 69.

${ }_{20}$ Resumen nacional... (1884), legajo 69.

${ }^{21}$ La Crisis Agricola y Pecuaria (1887-1889), tomo IV, p. 174. 


\section{GRAFICO 1}

Exportación de vino por el puerto de Málaga

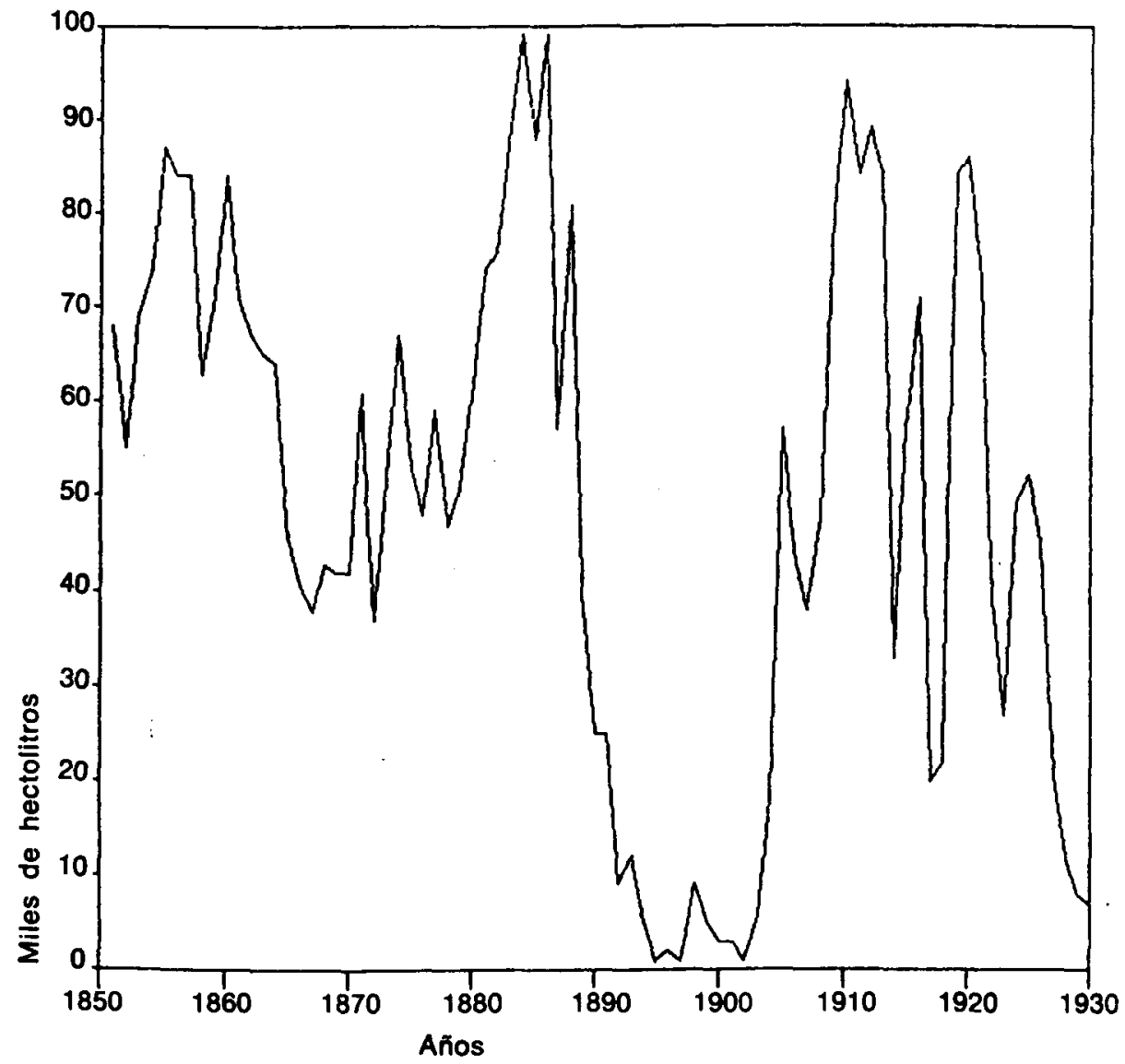

FuENTES: Elaboración propia a partir de Dirección General de Aduanas (1857.1920 b); Jiménez Blanco (1984), p. 961.

de la filoxera en Francia no creo que supusiera un incremento importante en la demanda de vinos malagueños. El vino obtenido en Málaga no se adecuaba a las exigencias de nuestro vecino país, que demandaba, especialmente, vino tinto común. Pero sí pudo provocar que por el puerto malacitano aumentaran las salidas de vinos de otras procedencias, como por ejemplo Valdepeñas, Montilla y Moguer ${ }^{22}$. Por lo tanto, creo que la recuperación

2 Información vinicola (1884), legajo 85. 
experimentada por las exportaciones de vino entre 1873 y 1886 pudo deberse a una mejora en la calidad del producto y a un incremento de las salidas de vinos de otras provincias, como consecuencia de la demanda francesa y llegados a Málaga a través del ferrocarril o del comercio de cabotaje.

En el gráfico 2 hemos recogido el vino entrado y salido por cabotaje por el puerto de Málaga. En dicho gráfico se observa que desde 1874 hasta 1901 las entradas experimentaron un crecimiento bastante importante. En esto pudo influir, por un lado, la caída de la producción malagueña de vino, ocurrida, tal y como veremos más adelante, desde 1884 hasta aproximadamente $1904, y$, por otro lado, el auge de la demanda francesa de vinos españoles que se prolongó de manera importante hasta 1892.

Las relativas esperanzas que se habían abrigado en la recuperación del sector sufrieron un duro golpe con la aparición de la filoxera en Málaga. Desde 1878 la plaga fue destruyendo con rapidez los viñedos y, de manera especial, las viñas viejas que eran precisamente las que proporcionaban los mejores mostos.

Los efectos de la plaga se dejaron sentir sobre la producción de mosto a partir de $1884^{23}$. Desde ese momento, y hasta los primeros años del presente siglo, la producción no dejó dé caer. Como dato significativo podemos decir que entre 1886 y 1904 la cantidad producida de mosto se redujo en un 96 por 100. Es muy probable que los efectos de la plaga fueran en realidad aún más graves. Digo esto porque la cifra de producción del año 1886, primer dato con el que contamos, era inferior a la de años anteriores. La Sociedad Económica de Amigos del País de Málaga decía en 1886 que la producción se hallaba en ese momento reducida en una quinta parte respecto a la de años precedentes ${ }^{24}$.

El vino malagueño, caro y de reducido consumo, era poco demandado, tanto desde el interior de la provincia como desde el extranjero. Por ello, a pesar de la reducción de la producción provocada a consecuencia de la filoxera, los vinateros de Málaga no encontraron compensación en una mejora de los precios. El resultado no pudo ser otro que una angustiosa crisis económica.

Las exportaciones de vino, como es natural, también se vieron muy afectadas, especialmente desde 1886. Como prueba de la crítica situación por la que se estaba atravesando, basta decir que entre 1892 y 1902 la cantidad de vino salida por el puerto malacitano fue ligeramente superior a la mitad de lo exportado en un solo año: 1886.

Con los primeros años del presente siglo se inició un cambio de coyun-

${ }^{23}$ Información vinicola (1884), legajo 85.

24 La Crisis Agricola y Pecuaria (1887-1889), tomo IV, p. 174. 


\section{GRAFICO 2}

Comercio de cabotaje. Entradas y salidas de vino. Aduana de Málaga

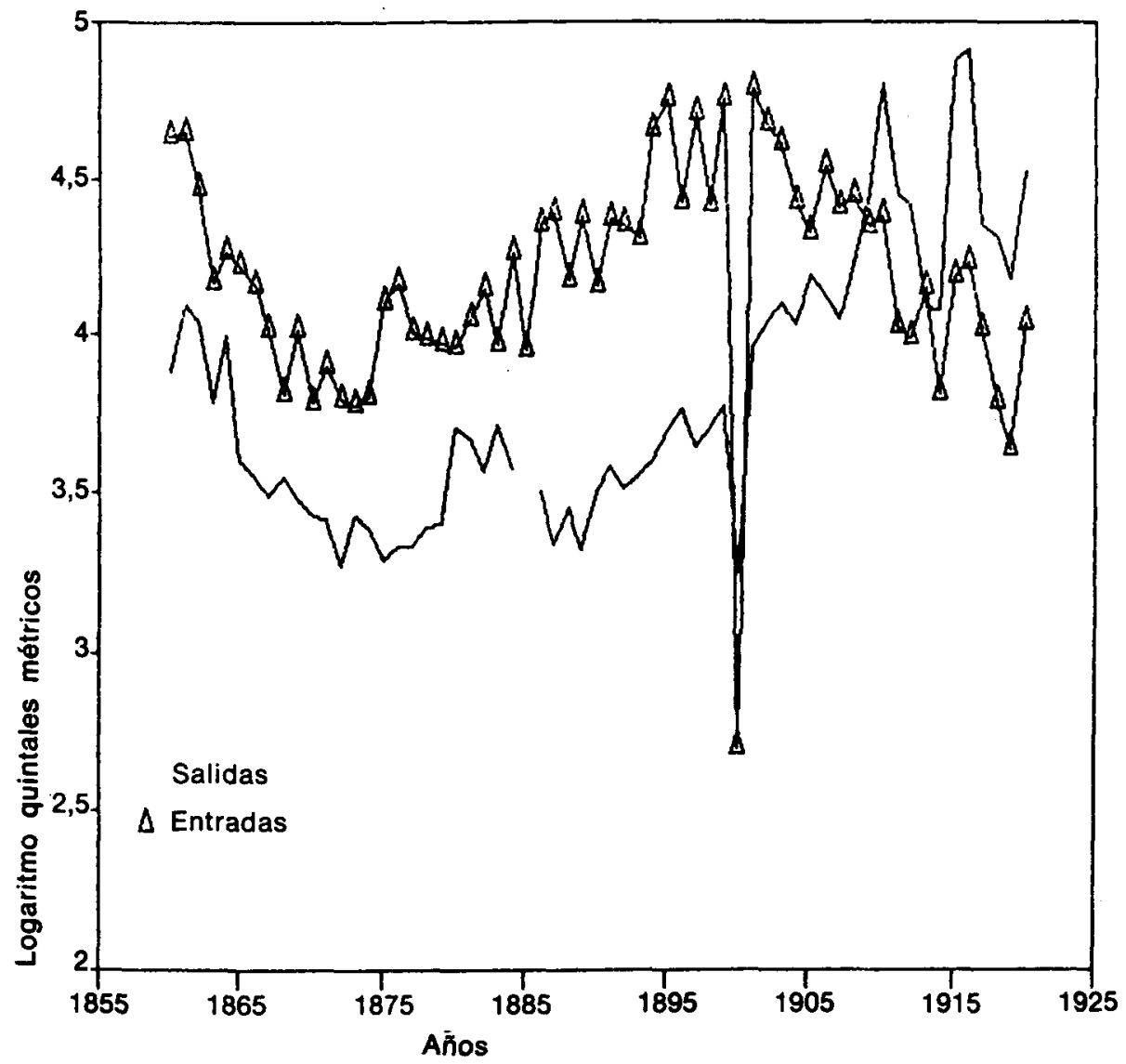

FuENTE: Elaboración propia a partir de Dirección General de Aduanas (1857-1920 a).

tura. Desde 1907 la producción de mosto experimentó una reactivación que duró, aproximadamente, hasta 1925, momento en el que se consiguió un mayor nivel, aunque todavía inferior al del año 1886. También las exportaciones mejoraron, especialmente hasta la Primera Guerra Mundial. Tras ella se inició una clara decadencia.

Por lo que respecta al comercio exterior, hay que señalar que efectivamente se produjo una mayor salida de vino por el puerto malagueño entre 


\section{GRAFICO 3}

Producción de mosto

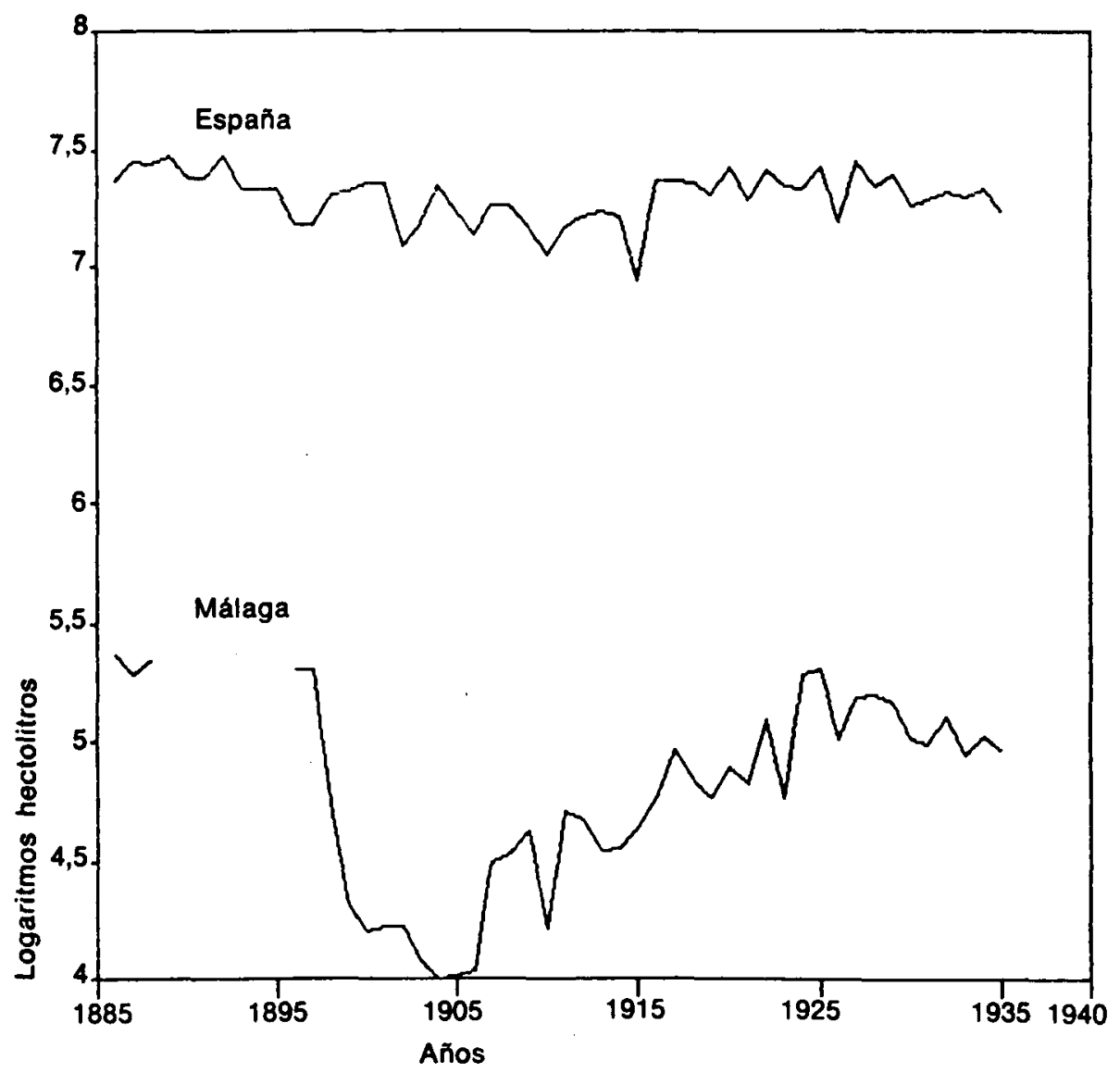

Fuente: Elaboración propia a partir de Jiménez Blanco (1984), pp. 958 y 959.

1903 y 1914, aunque claro está sin conseguir los niveles de 1886. Este incremento de las exportaciones obedeció a una mejora en la producción de vino y, sobre todo, a un aumento de los embarques de vino procedentes de otras provincias. En el gráfico 4 puede observarse que entre 1904 y 1916 en Málaga se exportó mucho más vino que el producido en la provincia.

La producción de mosto, como ya dijimos anteriormente, comenzó a recuperarse a partir de 1907. Entre 1906-1910 y 1926-1930, la cantidad produ- 
GRAFICO 4

Producción de mosto y exportación de vino. Málaga

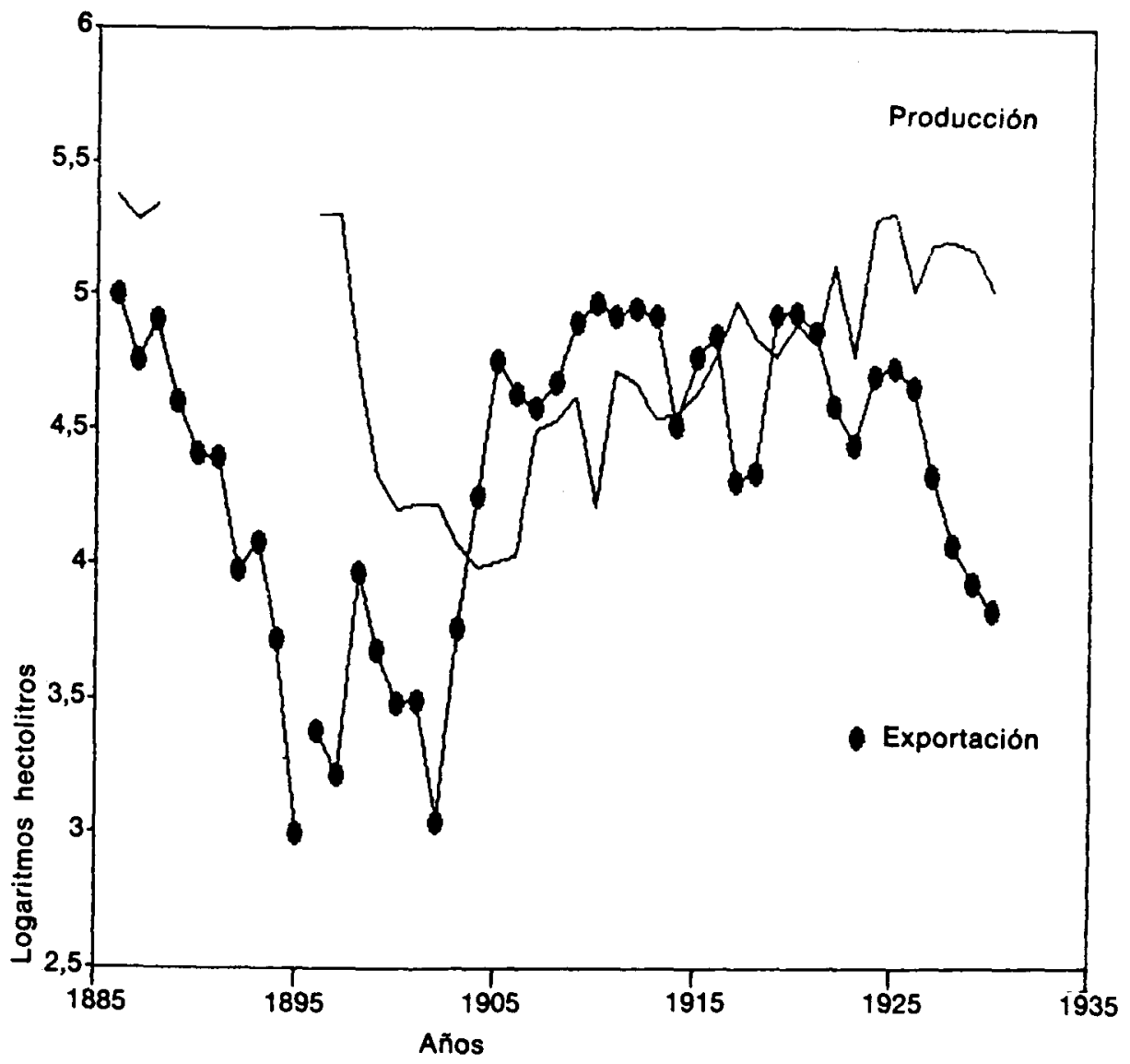

Fuentes: Elaboración propia a partir de Dirección General de Aduanas (1857-1920 b); Jiménez Blanco (1984), pp. 958-961.

cida de mosto se incrementó en un 396 por 100, tasa muy superior a la media nacional. Hay que tener en cuenta, naturalmente, el bajo punto de partida de Málaga. La mejora no se debió, al menos fundamentalmente, a una expansión del cultivo. La superficie de viñedos apenas creció un 27 por 100 a lo largo del período estudiado. Obedeció más que nada a un aumento de los rendimientos agrícolas $\mathrm{e}$ industriales. 
La replantación supuso, para aquellos campesinos que pudieron llevarla a cabo, un fuerte desembolso a la hora de comprar la planta y, posteriormente, unos elevados costes derivados de los especiales cuidados que exigían las nuevas cepas. Se hizo necesario, pues, incrementar la producción para compensar el alza de los costes.

\section{CUADRO 8 \\ Producción de mosto \\ (Hectolitros)}

\begin{tabular}{|c|c|c|c|c|}
\hline & \multicolumn{2}{|c|}{$M A L A G A$} & \multicolumn{2}{|c|}{ E S P A N $\mathbf{A}$} \\
\hline & A & B & $A$ & B \\
\hline $\begin{array}{lllllll}1906-1910 & \ldots & \ldots & \ldots & \ldots & \ldots & \ldots \\
1911-1915 & \ldots & \ldots & \ldots & \ldots & \ldots & \ldots \\
1916-1920 & \ldots & \ldots & \ldots & \ldots & \ldots & \ldots \\
1921-1925 & \ldots & \ldots & \ldots & \ldots & \ldots & \ldots \\
1926-1930 & \ldots & \ldots & \ldots & \ldots & \ldots & \ldots\end{array}$ & $\begin{array}{r}27.092 \\
42.621 \\
71.063 \\
128.092 \\
134.438\end{array}$ & $\begin{array}{l}100 \\
157 \\
262 \\
473 \\
496\end{array}$ & $\begin{array}{l}15.303 .087 \\
14.655 .044 \\
23.404 .416 \\
23.079 .353 \\
21.877 .807\end{array}$ & $\begin{array}{r}100 \\
96 \\
153 \\
151 \\
143\end{array}$ \\
\hline
\end{tabular}

A: Cantidad media del período.

B: Números índices.

FuenTE: Elaboración propia a partir de Jiménez Blanco (1984), pp. 958 y 959.

\section{CUADRO 9}

Superficie de viñedos

(Hectáreas)

\begin{tabular}{|c|c|c|c|c|}
\hline & \multicolumn{2}{|c|}{$M A L A G A$} & \multicolumn{2}{|c|}{ ES PAÑ A } \\
\hline & $\mathbf{A}$ & B & $\mathbf{A}$ & B \\
\hline $\begin{array}{lllllll}1906-1910 & \ldots & \ldots & \ldots & \ldots & \ldots & \ldots \\
1911-1915 & \ldots & \ldots & \ldots & \ldots & \ldots & \ldots \\
1916-1920 & \ldots & \ldots & \ldots & \ldots & \ldots & \ldots \\
1921-1925 & \ldots & \ldots & \ldots & \ldots & \ldots & \ldots \\
1926-1930 & \ldots & \ldots & \ldots & \ldots & \ldots & \ldots\end{array}$ & $\begin{array}{l}24.129 \\
24.191 \\
29.266 \\
29.936 \\
30.680\end{array}$ & $\begin{array}{l}100 \\
100 \\
121 \\
124 \\
127\end{array}$ & $\begin{array}{l}1.333 .264 \\
1.257 .486 \\
1.309 .603 \\
1.341 .436 \\
1.400 .023\end{array}$ & $\begin{array}{r}100 \\
94 \\
98 \\
101 \\
105\end{array}$ \\
\hline
\end{tabular}

A: Superficie media.

B: Números índices.

FurNTE: Elaboración propia a partir de Jiménez Blanco (1984), pp. 972 y 973. 
CUADRO $\cdot 10$

Producción de uva por bectárea

\begin{tabular}{|c|c|c|c|c|}
\hline & \multicolumn{2}{|c|}{$M A L A G A$} & \multicolumn{2}{|c|}{ ESPANA } \\
\hline & A & B & A & B \\
\hline $\begin{array}{lllllll}1906-1910 & \ldots & \ldots & \ldots & \ldots & \ldots & \ldots \\
1911-1915 & \ldots & \ldots & \ldots & \ldots & \ldots & \ldots \\
1916-1920 & \ldots & \ldots & \ldots & \ldots & \ldots & \ldots \\
1921-1925 & \ldots & \ldots & \ldots & \ldots & \ldots & \ldots \\
1926-1930 & \ldots & \ldots & \ldots & \ldots & \ldots & \ldots \\
19 & \ldots & \ldots & \ldots & \ldots\end{array}$ & $\begin{array}{l}15,06 \\
18,26 \\
20,91 \\
27,47 \\
31,69\end{array}$ & $\begin{array}{l}100 \\
121 \\
139 \\
182 \\
210\end{array}$ & $\begin{array}{l}19,75 \\
20,60 \\
30,16 \\
29,10 \\
25,88\end{array}$ & $\begin{array}{l}100 \\
104 \\
153 \\
147 \\
131\end{array}$ \\
\hline
\end{tabular}

A: Quintales métricos.

B: Números índices.

FuENTE: Elaboración propia a partir de Jiménez Blanco (1984), pp. 975 y 976.

\section{CUADRO 11}

Producción de mosto por bectárea

\begin{tabular}{|c|c|c|c|c|}
\hline & \multicolumn{2}{|c|}{$M A L A G A$} & \multicolumn{2}{|c|}{ ESPAN A } \\
\hline & $\mathbf{A}$ & B & A & B \\
\hline $\begin{array}{lllllll}1906-1910 & \ldots & \ldots & \ldots & \ldots & \ldots & \ldots \\
1911-1915 & \ldots & \ldots & \ldots & \ldots & \ldots & \ldots \\
1916-1920 & \ldots & \ldots & \ldots & \ldots & \ldots & \ldots \\
1921-1925 & \ldots & \ldots & \ldots & \ldots & \ldots & \ldots \\
1926-1930 & \ldots & \ldots & \ldots & \ldots & \ldots & \ldots \\
\end{array}$ & $\begin{array}{r}5,33 \\
6,44 \\
9,46 \\
15,39 \\
17,98\end{array}$ & $\begin{array}{l}100 \\
121 \\
177 \\
289 \\
337\end{array}$ & $\begin{array}{l}12,24 \\
12,66 \\
19,05 \\
18,26 \\
16,60\end{array}$ & $\begin{array}{l}100 \\
103 \\
156 \\
149 \\
136\end{array}$ \\
\hline
\end{tabular}

A: Hectolitros.

B: Números índices.

Fuente: Elaboración propia a partir de Jiménez Blanco (1984), pp. 975-979.

A lo largo de los aproximadamente treinta primeros años del presente siglo, se produjo un importante incremento de los rendimientos agrícolas e industriales. Entre 1906-1910 y 1926-1930, la cantidad de uva obtenida por unidad de superficie se incrementó en un 110 por 100 , mientras que la de mosto lo hizo aún más, un 237 por 100 . Estos porcentajes son una prueba evidente de que en Málaga hubo algunos intentos por revitalizar el 
sector. Algo se consiguió, pero lo cierto es que los sistemas de cultivo y las técnicas de elaboración seguían todavía dejando bastante que desear. Prueba de ello es que a pesar del crecimiento experimentado en los niveles de producción, éstos fueron a lo largo del período estudiado, y a excepción hecha de los años 1926-1930, inferiores a los nacionales.

\subsection{La pasa de Málaga}

El proceso de elaboración de la afamada pasa de sol malagueña era muy complejo, empleándose en el mismo gran cantidad de tiempo y de trabajo. Esto hacía de ella una mercancía cara y, por lo tanto, con una demanda muy selecta.

Hasta el inicio de la década de los años setenta del siglo pasado, la pasa de sol conoció un período de gran esplendor. La causa del mismo hay que buscarla en una demanda exterior muy importante. Era el mercado americano, y especialmente el estadounidense, el que requería la mayor parte de las ventas malagueñas al exterior. Fueron unos años caracterizados por un importante incremento de las exportaciones. Se vendió más y, además, parece ser que a mejor precio ${ }^{25}$, lo que sin duda redundó en un aumento de los ingresos de los productores. Esta fase expansiva duró hasta el año 1872. Desde entonces, $y$ hasta 1895 , las exportaciones de pasas malagueñas cayeron en picado. Esto no concuerda con lo ocurrido a nivel nacional, donde las exportaciones se mantuvieron prácticamente estabilizadas durante dicho período de tiempo. ¿Por qué se produjo la decadencia de la pasa malagueña?

Como puede observarse en el gráfico 6, fue a partir de 1872 cuando de forma paulatina comenzó a perderse el mercado americano. Esto supuso un duro golpe para el sector, ya que a dicho mercado se dirigían la mayor parte de las exportaciones. Prueba de ello es que en 1880, año en el que las ventas ya habían descendido, el mercado estadounidense adquirió más de la mitad de todo lo cosechado en la provincia de Málaga ${ }^{26}$. ¿Por qué Estados Unidos redujo su demanda de pasas malagueñas?

A ello contribuyó la cada vez más importante producción autóctona. En el Estado de California, y especialmente en los departamentos de San Diego, San Bernardino, Los Angeles y Fresno ${ }^{27}$, la industria de la pasa fue poco a poco desarrollándose al amparo de varias medidas de carácter proteccionista. Con el paso del tiempo la producción americana sustituiría a la importación de pasas de Málaga.

${ }^{23}$ Morilla (1974), p. 84.

${ }^{26}$ Morilla (1974), p. 84.

27 Unión Mercantil (1887). 


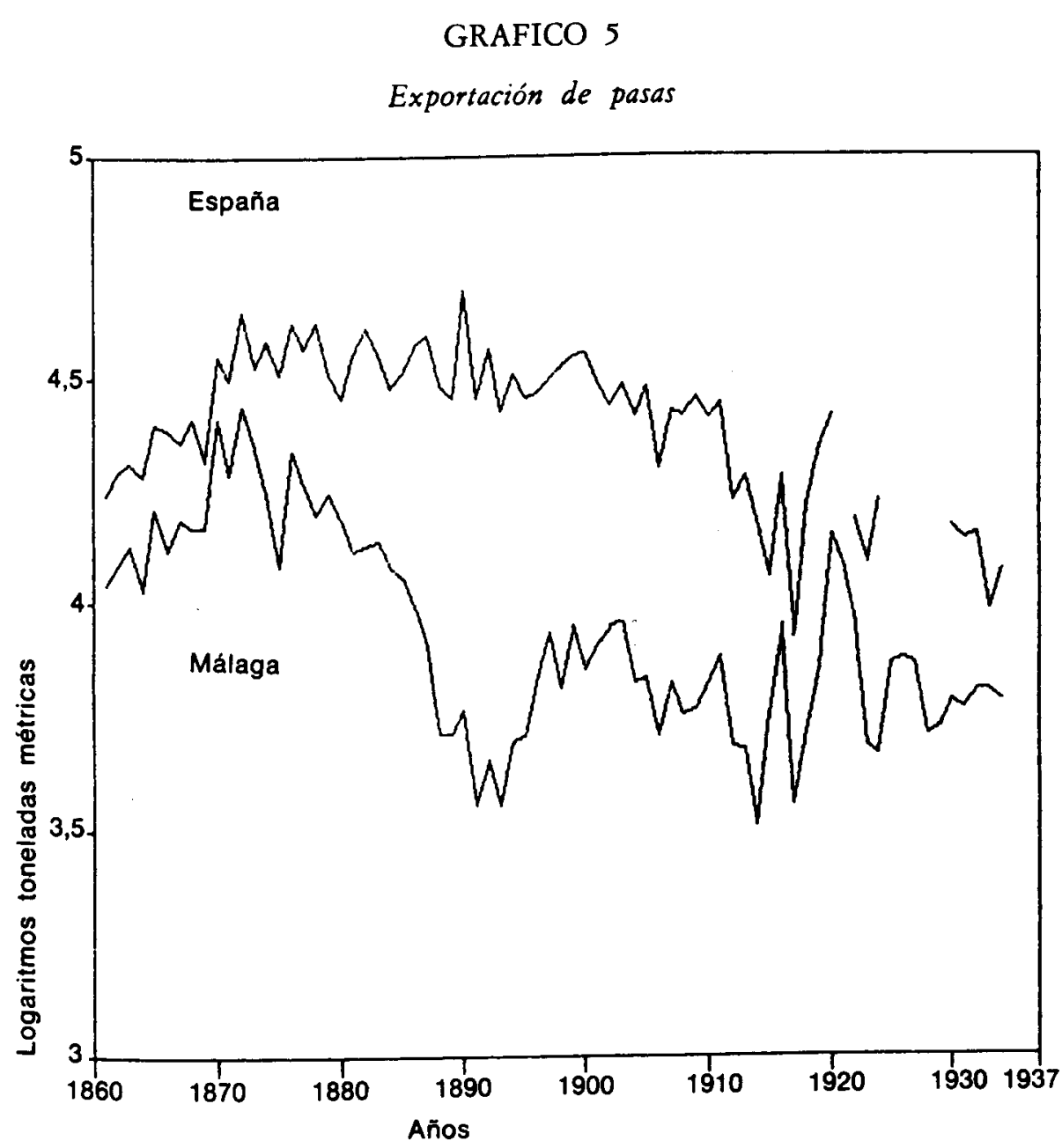

FuENTEs: Elaboración propia a partir de Dirección General de Aduanas (1857-1920 b); Jiménez Blanco (1984), pp. 964-967.

Como puede observarse en el cuadro 12 esto no ocurriria hasta aproximadamente el año 1885. Sin embargo, hemos visto que desde 1872 disminuyeron las ventas a América. La pérdida del mercado americano no obedeció, pues, exclusivamente al crecimiento de la producción americana, sino también a la competencia ejercida por países como Grecia y Turquía. Las pasas de Corinto gozaron de ventajas arancelarias, tanto en Estados Unidos como 


\section{GRAFICO 6}

Destino de las exportaciones de pasas realizadas por el puerto de Málaga

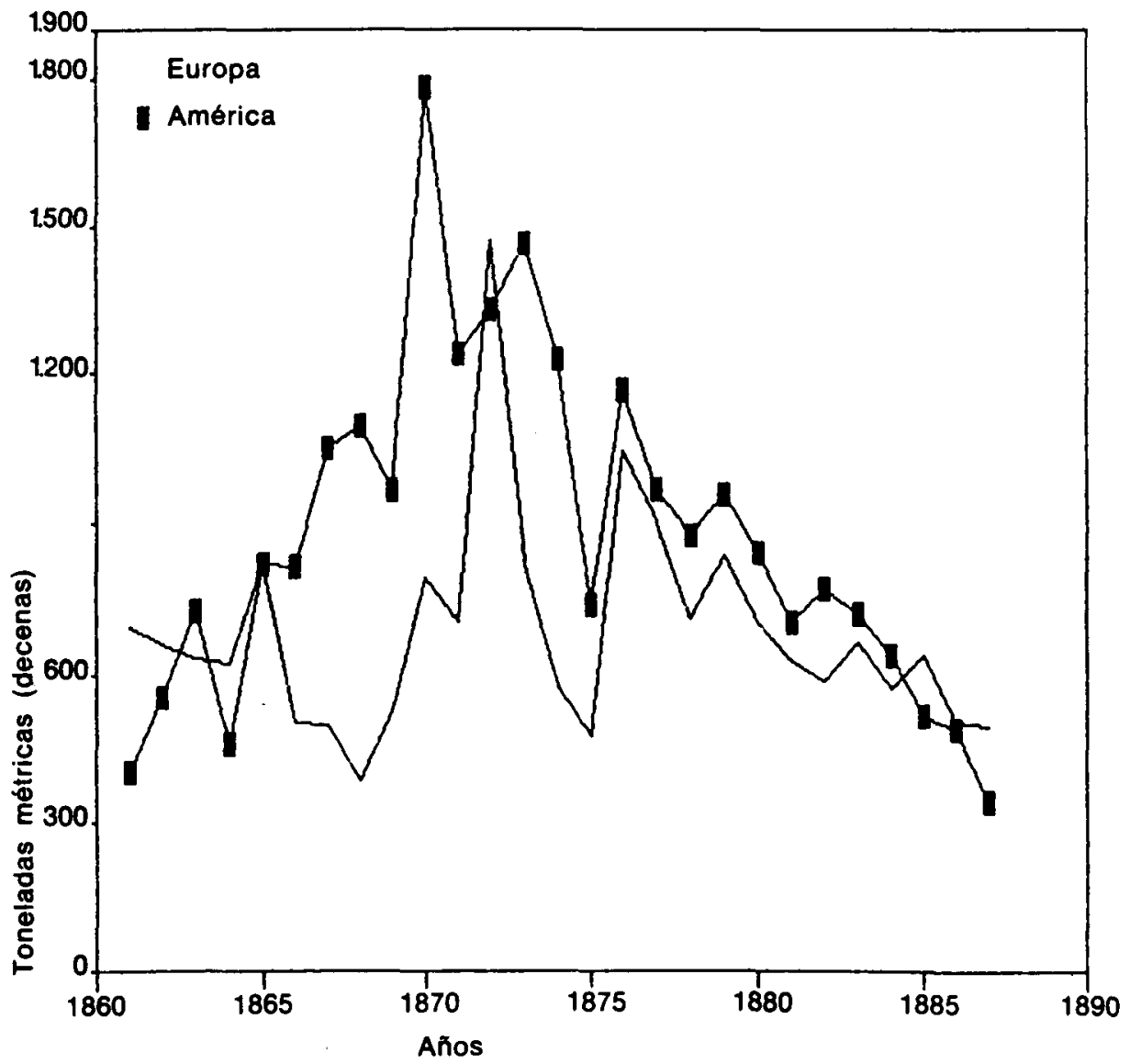

Fuente: Elaboración propia a partir de Dirección General de Aduanas (1857-1920 b).

en Inglaterra. Esta competencia afectó a la pasa malgueña en los mercados americanos y también en los europeos. Esta situación desembocó en un descenso de los precios.

Otro factor que contribuyó a agravar la situación fue la realización de prácticas fraudulentas. Como las pasas se vendían por cajas, había comerciantes que introducían irregularidades en el peso de las mismas. También se recibían quejas desde el extranjero porque las cajas llegaban comṕletamente 


\section{CUADRO 12}

\section{Exportación de pasa malagueña a Estados Unidos $y$ producción californiana}

(Cajas)

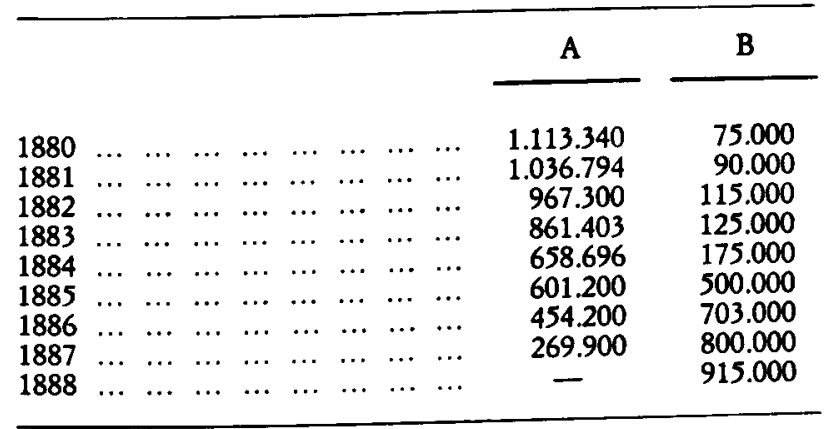

A: Exportación de pasa de Málaga a Estados Unidos.

B: Pasa envasada en California.

Fuente: Morilla Critz (1974), p. 81.

deshechas a sus puntos de destino, unas veces debido a las malas condiciones de la madera y otras al deficiente empaquetado ${ }^{28}$.

Así de grave era la situación, caída de las exportaciones y de precios, cuando la filoxera irrumpió en Málaga en 1878. La plaga asoló los campos $\mathrm{y}$, por lo tanto, se redujo la producción. Esto, que normalmente bubiera ocasionado un incremento de los precios, con lo que se hubieran podido resarcir los productores, no fue así debido a que no había demanda.

El hundimiento de la producción a consecuencia de la filoxera vino precedido, pues, de una pérdida de mercado. Esto explica el por qué tras la plaga no se volvió a replantar toda la superficie de viñedos. No obstante, y a pesar de las dificultades por las que atravesaba el comercio de la pasa, los viticultores malagueños prefirieron utilizar la variedad Moscatel a la hora de reconstituir el viñedo destruido por la filoxera con patrones americanos. Dicha variedad, destinada básicamente a la pasificación, aumentó su importancia relativa tras la replantación. Antes de la invasión representaba el 40 por 100 de todo el viñedo, mientras que en 1909 suponía el 74 por $100^{29}$. La preferencia por la variedad Moscatel se explica por el precio remune-

\footnotetext{
${ }^{23}$ Unión Mercantil (1886).

Ministerio de Fomento, Dirección General de Agricultura, Industria y Comercio (1911), pp. 149 y 150 .
} 
rador que alcanzaban las pasas típicas de Málaga en comparación con la baja experimentada en el precio de los mostos, influida por la concurrencia de los de otras localidades, con lo que, de mejor o peor manera, se sofisticaron los antiguos tipos de la provincia.

\section{LA CRISIS POBLACIONAL MALAGUEÑA DE FINALES DEL SIGLO XIX}

La crisis económica y social por la que atravesó Málaga a lo largo del último cuarto del siglo xix y primeros años del siglo $\mathrm{xx}$ repercutió muy negativamente desde un punto de vista poblacional. Entre 1860 y 1930 Málaga fue, tras Almería, la provincia andaluza que registró un menor crecimiento poblacional.

CUADRO 13

Evolución población provincias andaluzas

(Números índices: $1860=100$ )

\begin{tabular}{|c|c|c|c|c|c|c|c|}
\hline & 1877 & 1887 & 1897 & 1900 & 1910 & 1920 & 1930 \\
\hline 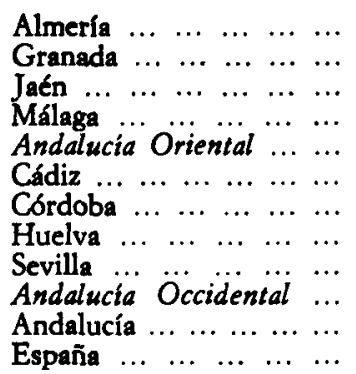 & $\begin{array}{l}111 \\
108 \\
117 \\
112 \\
112 \\
107 \\
107 \\
119 \\
107 \\
108 \\
110 \\
106\end{array}$ & $\begin{array}{l}108 \\
110 \\
121 \\
116 \\
114 \\
107 \\
117 \\
144 \\
115 \\
117 \\
115 \\
112\end{array}$ & $\begin{array}{l}109 \\
108 \\
128 \\
109 \\
113 \\
108 \\
124 \\
144 \\
115 \\
119 \\
116 \\
116\end{array}$ & $\begin{array}{l}114 \\
111 \\
131 \\
115 \\
117 \\
113 \\
127 \\
148 \\
117 \\
122 \\
120 \\
119\end{array}$ & $\begin{array}{l}120 \\
118 \\
145 \\
117 \\
125 \\
117 \\
139 \\
175 \\
126 \\
133 \\
129 \\
127\end{array}$ & $\begin{array}{l}113 \\
130 \\
163 \\
124 \\
133 \\
136 \\
158 \\
187 \\
148 \\
152 \\
142 \\
136\end{array}$ & $\begin{array}{l}108 \\
146 \\
186 \\
137 \\
145 \\
139 \\
186 \\
201 \\
170 \\
169 \\
156 \\
151\end{array}$ \\
\hline
\end{tabular}

Fuente: Elaboración propia a partir de los Censos Oficiales de Población. Considero como población española la de la Península, islas adyacentes, norte y costa occidental de Africa. Considero como población andaluza la de las ocho provincias más la plaza de Ceuta, incluida en todo momento en la provincia de Cádiz. 


\section{CUADRO 14}

\section{Evolución población malagueña}

\begin{tabular}{|c|c|c|c|c|c|}
\hline & (1) & (2) & (3) & (4) & (5) \\
\hline $\begin{array}{llllll}1860 & \ldots & \ldots & \ldots & \ldots & \ldots \\
1877 & \ldots & \ldots & \ldots & \ldots & \ldots \\
1887 & \ldots & \ldots & \ldots & \ldots & \ldots \\
1897 & \ldots & \ldots & \ldots & \ldots & \ldots \\
1900 & \ldots & \ldots & \ldots & \ldots & \ldots \\
1910 & \ldots & \ldots & \ldots & \ldots & \ldots \\
1920 & \ldots & \ldots & \ldots & \ldots & \ldots \\
1930 & \ldots & \ldots & \ldots & \ldots & \ldots\end{array}$ & $\begin{array}{l}446.659 \\
500.322 \\
519.377 \\
485.132 \\
511.989 \\
523.412 \\
554.301 \\
613.160\end{array}$ & $\begin{array}{r}-\overline{53.663} \\
19.055 \\
-34.245 \\
26.857 \\
11.423 \\
30.889 \\
58.859\end{array}$ & $\begin{array}{r}\overline{0,66} \\
0,37 \\
-0,68 \\
1,79 \\
0,22 \\
0,57 \\
1,01\end{array}$ & $\begin{array}{l}61,4 \\
68,8 \\
71,4 \\
66,7 \\
70,4 \\
71,9 \\
76,2 \\
84,3\end{array}$ & $\begin{array}{l}100 \\
112 \\
116 \\
109 \\
115 \\
117 \\
124 \\
137\end{array}$ \\
\hline
\end{tabular}

(1) Población total.

(2) Crecimiento período intercensal.

(3) Tasa media anual de crecimiento intercensal (\%).

(4) Densidad.

(5) Números índices.

Fuente: Elaboración propia a partir de los Censos Oficiales de Población.

\section{CUADRO 15}

Evolución población española

\begin{tabular}{|c|c|c|c|c|c|}
\hline & (1) & (2) & (3) & (4) & (5) \\
\hline $\begin{array}{llllll}1860 & \ldots & \ldots & \ldots & \ldots & \\
1877 & \ldots & \ldots & \ldots & \ldots & \ldots \\
1887 & \ldots & \ldots & \ldots & \ldots & \ldots \\
1897 & \ldots & \ldots & \ldots & \ldots & \ldots \\
1900 & \ldots & \ldots & \ldots & \ldots & \ldots \\
1910 & \ldots & \ldots & \ldots & \ldots & \ldots \\
1920 & \ldots & \ldots & \ldots & \ldots & \ldots \\
1930 & \ldots & \ldots & \ldots & \ldots & \ldots \\
19\end{array}$ & $\begin{array}{l}15.673 .481 \\
16.634 .345 \\
17.565 .632 \\
18.132 .475 \\
18.618 .086 \\
19.995 .446 \\
21.389 .842 \\
23.677 .794\end{array}$ & $\begin{array}{r}-\overline{960.864} \\
931.287 \\
566.843 \\
485.611 \\
1.377 .360 \\
1.394 .396 \\
2.287 .952\end{array}$ & $\begin{array}{l}\overline{0,35} \\
0,54 \\
0,32 \\
0,88 \\
0,71 \\
0,67 \\
1,01\end{array}$ & $\begin{array}{l}31,0 \\
32,9 \\
34,8 \\
35,9 \\
36,8 \\
39,6 \\
42,3 \\
46,9\end{array}$ & $\begin{array}{l}100 \\
106 \\
112 \\
116 \\
119 \\
127 \\
136 \\
151\end{array}$ \\
\hline
\end{tabular}

(1) Población total.

(2) Crecimiento período intercensal.

(3) Tasa media anual de crecimiento intercensal (\%).

(4) Densidad.

(5) Números índices.

Fuente: Elaboración propia a partir de los Censos Oficiales de Población. 


\section{CUADRO 16}

Evolución población andaluza

\begin{tabular}{|c|c|c|c|c|c|}
\hline & (1) & (2) & (3) & (4) & (5) \\
\hline $\begin{array}{llllll}1860 & \ldots & \ldots & \ldots & \ldots & \ldots \\
1877 & \ldots & \ldots & \ldots & \ldots & \ldots \\
1887 & \ldots & \ldots & \ldots & \ldots & \ldots \\
1897 & \ldots & \ldots & \ldots & \ldots & \ldots \\
1900 & \ldots & \ldots & \ldots & \ldots & \ldots \\
1910 & \ldots & \ldots & \ldots & \ldots & \ldots \\
1920 & \ldots & \ldots & \ldots & \ldots & \ldots \\
1930 & \ldots & \ldots & \ldots & \ldots & \ldots \\
193\end{array}$ & $\begin{array}{l}2.976 .882 \\
3.283 .436 \\
3.431 .555 \\
3.455 .659 \\
3.562 .606 \\
3.828 .916 \\
4.225 .667 \\
4.660 .493\end{array}$ & $\begin{array}{r}-\overline{3} \\
306.554 \\
148.119 \\
24.104 \\
106.947 \\
266.310 \\
396.751 \\
434.826\end{array}$ & $\begin{array}{l}\overline{0,58} \\
0,44 \\
0,07 \\
1,01 \\
0,72 \\
0,98 \\
0,98\end{array}$ & $\begin{array}{l}34,1 \\
37,6 \\
39,3 \\
39,6 \\
40,8 \\
43,8 \\
48,4 \\
53,4\end{array}$ & $\begin{array}{l}100 \\
110 \\
115 \\
116 \\
120 \\
129 \\
142 \\
156\end{array}$ \\
\hline
\end{tabular}

(1) Población total.

(2) Crecimiento período intercensal.

(3) Tasa media anual de crecimiento intercensal (\%).

(4) Densidad.

(5) Números índices.

Fuente: Elaboración propia a partir de los Censos Oficiales de Población.

Entre 1860 y 1877 la favorable coyuntura económica que vivió la provincia facilitó que la población aumentara a un buen ritmo, siendo su tasa media anual de crecimiento, 0,66 por 100 , bastante superior a la nacional, 0,35 por 100 , y regional, 0,58 por 100 . Gracias al desarrollo de sus industrias siderúrgica y textil, Málaga era un foco temprano de industrialización, y prueba de ello es que su porcentaje de activos empleados en el sector secundario era superior a los valores nacionales (cuadro 17) ${ }^{30}$. La situación comenzó a cambiar a partir de 1878 , momento en el que se inició una etapa que duró aproximadamente hasta final de siglo y que trajo graves consecuencias para la población. Las crisis agrícola, industrial y comercial produjeron efectos muy negativos en la evolución demográfica provincial.

Entre 1877 y 1887 Málaga creció todavía a un ritmo moderado, pero inferior ya a las medias andaluza y española. El período más dramático fue el comprendido entre 1887 y 1897 , en el que la población malagueña se redujo en un 6,6 por 100 , algo que no ocurrió en ninguna otra provincia andaluza. El aumento del paro agrícola e industrial —en 1900 el porcentaje

so En el cuadro 17, y a la hora de agrupar por sectores, hemos seguido los criterios utilizados por Gil Ibáñez (1979), excepto en el caso de la población dedicada al transporte, que él incluye en el sector secundario y nosotros en el terciario. Hemos considerado como población española la de la Península, islas adyacentes, norte y costa occidental de Africa. 


\section{CUADRO 17}

Distribución sectorial de la población ocupada (\%)

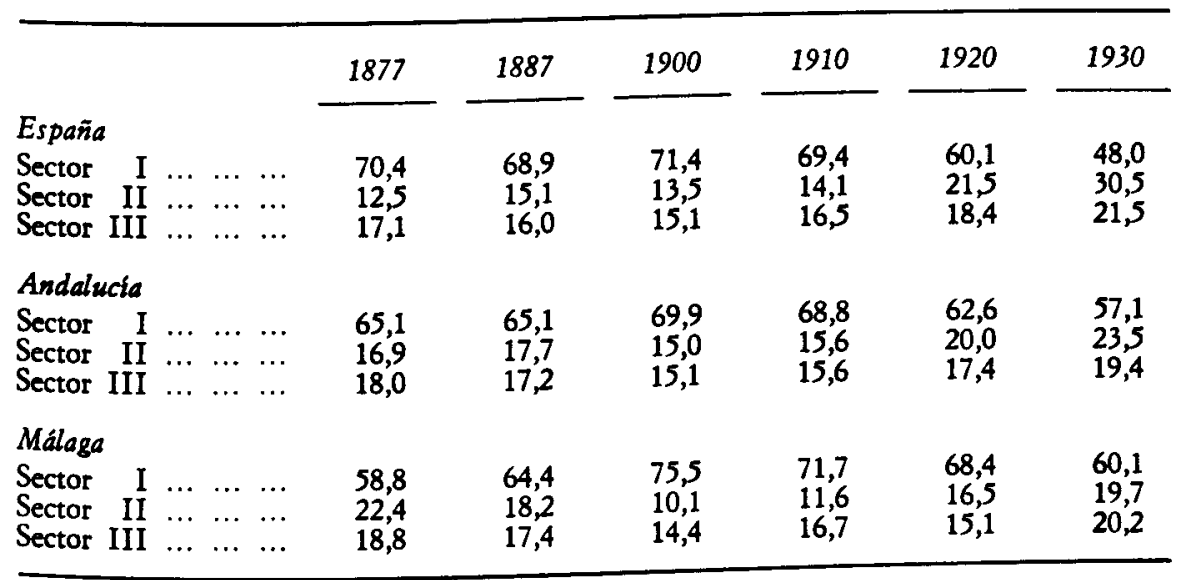

Fuente: Elaboración propia a partir de los Censos Oficiales de Población.

\section{CUADRO 18}

Tasas de migración (\%o)

\begin{tabular}{|c|c|c|c|c|c|c|}
\hline & $1878-87$ & $1888-97$ & $\begin{array}{l}1898- \\
1900\end{array}$ & $1901-10$ & $1911-20$ & $1921-30$ \\
\hline 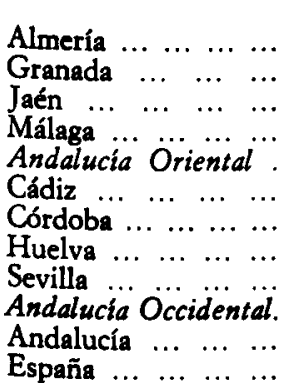 & $\begin{array}{r}-5,55 \\
-1,48 \\
-1,12 \\
-0,76 \\
-1,98 \\
-0,62 \\
3,07 \\
11,30 \\
3,39 \\
3,38 \\
0,56 \\
0,87\end{array}$ & $\begin{array}{r}3,50 \\
-4,32 \\
3,24 \\
-10,51 \\
-3,99 \\
-1,06 \\
2,38 \\
-7,70 \\
-1,12 \\
-1,20 \\
-2,64 \\
-2,00\end{array}$ & $\begin{array}{r}8,68 \\
4,35 \\
0,14 \\
13,29 \\
6,56 \\
10,65 \\
4,94 \\
0,19 \\
2,03 \\
4,76 \\
5,69 \\
3,66\end{array}$ & $\begin{array}{r}-4,05 \\
-3,97 \\
0,14 \\
-6,27 \\
-3,53 \\
-4,05 \\
-1,02 \\
6,03 \\
0,40 \\
-0,22 \\
-1,92 \\
-2,19\end{array}$ & $\begin{array}{r}-12,88 \\
1,34 \\
3,85 \\
-1,02 \\
-1,19 \\
10,26 \\
3,02 \\
-0,96 \\
11,22 \\
6,87 \\
2,83 \\
0,40\end{array}$ & $\begin{array}{r}-19,84 \\
-2,50 \\
-1,27 \\
-1,01 \\
-4,53 \\
-7,95 \\
3,44 \\
-0,07 \\
4,21 \\
0,38 \\
-2,02 \\
-0,02\end{array}$ \\
\hline
\end{tabular}

FUENTES: Elaboración propia a partir de Dirección General del Instituto Geográfico y Estadístico (1888), Movimientos Naturales de la Población y Censos Oficiales de Población. Ceuta está incluida en Cádiz, y considero como población española la de la Península, islas adyacentes y Ceuta. 
de activos empleados en el sector industrial era ya en Málaga inferior a los valores españoles y andaluces- y la ruina de gran parte de los pequeños propietarios agrarios propiciaron que la emigración fuera la única alternativa.

Entre 1888 y 1897 la emigración malagueña superó a la inmigración en $\mathbf{5 2 . 8 2 3}$ personas. Este saldo migratorio negativo fue el más elevado de los registrados en Andalucía y representó el 58 por 100 de la pérdida poblacional de toda la región.

Esta fuerte corriente emigratoria se vio frenada tras la pérdida de las últimas posesiones españolas en ultramar. Entre 1898 y 1900 Málaga contempló cómo llegaban a sus lares más personas que las que los abandonaban, concretamente 19.891. En estos años netamente inmigratorios, la tasa de migración malagueña fue la más elevada de las registradas en Andalucía y superó también ampliamente a la media nacional ${ }^{31}$.

Málaga entró en el nuevo siglo con una población inferior en términos absolutos a la existente en 1887, siendo la única provincia andaluza donde ocurrió tal fenómeno, y con unas perspectivas nada favorables para su economía. La agricultura estaba depauperada, sobre todo el sector vitivinícola, el comercio y la industria textil muy debilitados y arruinada la industria siderúrgica. Bajo estos condicionantes era lógico que Málaga no participara del gran alza demográfica experimentada en España entre 1900 y 1930.

En la primera década del presente siglo las salidas volvieron a superar a las entradas y Málaga sufrió de nuevo una importante pérdida de población, 32.494 personas, siendo la más destacada de las registradas en la región andaluza. En los dos decenios siguientes los saldos migratorios continuaron siendo negativos, pero las pérdidas poblacionales fueron ya mucho menos importantes. Sólo en la tercera década del siglo, y como consecuencia de una cierta mejoría económica, se observaron en la población malagueña indicios de recuperación.

El momento álgido de la emigración malagueña fue, pues, el comprendido entre 1888 y 1910 , años en los que Málaga perdió 65.426 habitantes, el 94 por 100 del crecimiento vegetativo del período. Las Estadísticas de Emigración parecen confirmar la aseveración anterior. Entre 1888 y 1910, 96.312 personas salieron por el puerto malacitano, tercero en importancia a nivel regional tras los de Cádiz y Almería, a un ritmo anual de 4.187 pasajeros. Los períodos de máxima intensidad emigratoria fueron los comprendidos entre 1882-1892 y 1904-1910. Tal y como ocurrió a nivel nacional, los

"Al comparar en los cuadros los datos de 1897 con los de 1900 se observa un crecimiento poblacional muy importante. En este hecho pudo influir desde la pérdida de las últimas posesiones españolas de ultramar, con la consiguiente llegada de repatriados y el aumento de dificultades para la emigración, hasta posibles diferencias a la hora de elaborar los datos de los respectivos censos. 
años siguientes al desastre colonial fueron aquellos en donde el número de emigrantes fue más reducido ${ }^{32}$.

Hemos visto cómo entre 1860 y 1930 la evolución demográfica de la provincia de Málaga no fue en absoluto homogénea desde un punto de vista temporal. Tampoco lo fue geográficamente. La población se distribuyó de manera desequilibrada entre las distintas comarcas existentes en la provincia.

\section{CUADRO 19}

Evolución población comarcas malagueñas

(Números índices: $1860=100$ )

\begin{tabular}{|c|c|c|c|c|c|}
\hline & Litoral & Hoya & Depresión & Serrania & Axarquía \\
\hline $1877 \ldots \ldots \ldots \ldots$ & 119 & 116 & 107 & 110 & 101 \\
\hline $\begin{array}{lllllll}1887 & \ldots & \ldots & \ldots & \ldots & \ldots\end{array}$ & 131 & 125 & 113 & 109 & 87 \\
\hline $1897 \ldots \ldots \ldots \ldots$ & 122 & 113 & 108 & 103 & 78 \\
\hline $1900 \ldots \ldots \ldots \ldots$ & 128 & 125 & 120 & 100 & 82 \\
\hline $1910 \ldots \ldots \ldots \ldots$ & 131 & 127 & 123 & 105 & 83 \\
\hline $1920 \ldots \ldots \ldots \ldots$ & 139 & 136 & 128 & 114 & 87 \\
\hline $1930 \ldots \ldots \ldots$ & 163 & 147 & 137 & 119 & 89 \\
\hline
\end{tabular}

Furnte: Elaboración propia a partir de los Censos Oficiales de Población.

\subsection{El Litoral}

La comarca que tuvo un aumento poblacional más importante fue el Litoral. Esta región comprende todos los municipios costeros de la provincia, incluida la capital. El municipio de Málaga, por su capitalidad, su condición de ciudad marítima y por ser el centro administrativo, comercial y mercantil, fue el que registró un crecimiento más destacado, condicionando a su vez la evolución demográfica de toda la comarca.

La capital de la provincia tuvo un comportamiento demográfico hasta cierto punto similar al del resto de la provincia, aunque con unos índices de crecimiento muy superiores.

\footnotetext{
${ }^{32}$ Elaborado a partir de las Estadísticas de Emigración e Inmigración.
} 
CUADRO 20

Evolución población. Comarca: Litoral

\begin{tabular}{|c|c|c|c|c|c|}
\hline & (1) & (2) & (3) & (4) & (5) \\
\hline $\begin{array}{llllll}1860 & \ldots & \ldots & & & \\
1860 & \ldots & \ldots & \ldots & \ldots \\
1877 & \ldots & \ldots & \ldots & \ldots & \ldots \\
1887 & \ldots & \ldots & \ldots & \ldots & \ldots \\
1897 & \ldots & \ldots & \ldots & \ldots & \ldots \\
1900 & \ldots & \ldots & \ldots & \ldots & \ldots \\
1910 & \ldots & \ldots & \ldots & \ldots & \ldots \\
1920 & \ldots & \ldots & \ldots & \ldots & \ldots \\
1930 & \ldots & \ldots & \ldots & \ldots & \ldots\end{array}$ & $\begin{array}{l}168.943 \\
200.530 \\
221.050 \\
206.572 \\
217.516 \\
222.001 \\
234.924 \\
275.341\end{array}$ & $\begin{array}{r}-\overline{31.587} \\
20.520 \\
-14.478 \\
10.944 \\
4.485 \\
12.923 \\
40.417\end{array}$ & $\begin{array}{r}\overline{1,00} \\
0,97 \\
-0,67 \\
1,72 \\
0,20 \\
0,56 \\
1,58\end{array}$ & $\begin{array}{l}140 \\
166 \\
183 \\
171 \\
180 \\
184 \\
195 \\
228\end{array}$ & $\begin{array}{l}100 \\
119 \\
131 \\
122 \\
128 \\
131 \\
139 \\
163\end{array}$ \\
\hline
\end{tabular}

(1) Población total.

(2) Crecimiento período intercensal.

(3) Tasa media anual de crecimiento intercensal (\%).

(4) Densidad.

(5) Números índices.

Fuente: Elaboración propia a partir de los Censos Oficiales de Población.

Entre 1860 y 1930 Málaga fue la segunda capital de Andalucía con mayor número de habitantes y experimentó un crecimiento del 90 por 100 , porcentaje muy similar al registrado en las capitales andaluzas y bastante inferior al de las capitales españolas. La tasa media anual de crecimiento fue del 0,88 por 100 en Málaga, por un 0,85 por 100 en Andalucía y un 1,33 por 100 en España.

\section{CUADRO 21}

Evolución población. Málaga capital

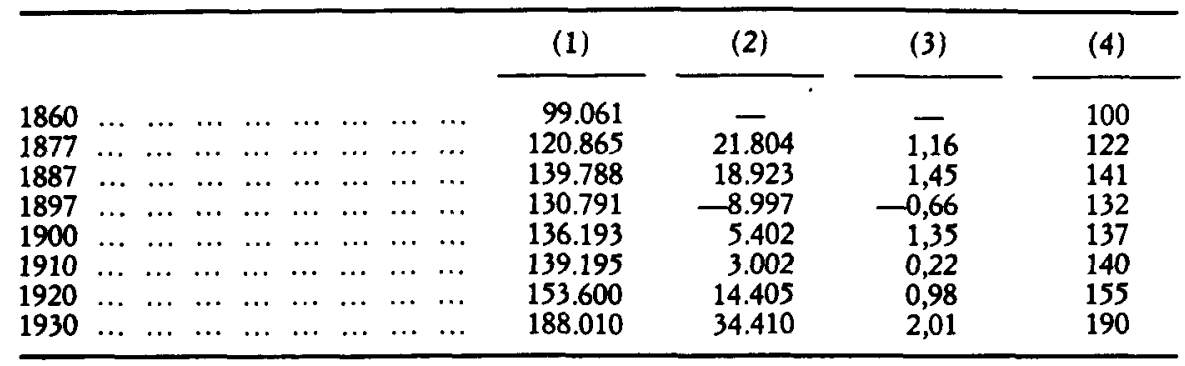

(1) Pobleción total.

(2) Crecimiento período intercensal.

(3) Tasa media anual de crecimiento intercensal (\%).

(4) Números índices.

Fuente: Elaboración propia a partir de los Censos Oficiales de Población. 


\section{CUADRO 22}

Evolución población capitales

(Números índices: $1860=100$ )

\begin{tabular}{|c|c|c|c|c|c|c|c|}
\hline & 1877 & 1887 & 1897 & 1900 & 1910 & 1920 & 1930 \\
\hline 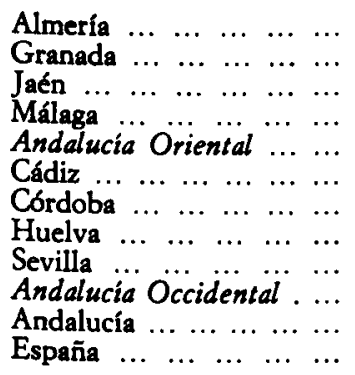 & $\begin{array}{r}137 \\
113 \\
106 \\
122 \\
119 \\
91 \\
118 \\
134 \\
113 \\
108 \\
114 \\
122\end{array}$ & $\begin{array}{l}123 \\
108 \\
112 \\
141 \\
125 \\
87 \\
132 \\
185 \\
121 \\
116 \\
120 \\
136\end{array}$ & $\begin{array}{r}159 \\
111 \\
113 \\
132 \\
127 \\
98 \\
136 \\
201 \\
123 \\
121 \\
124 \\
161\end{array}$ & $\begin{array}{r}161 \\
113 \\
115 \\
137 \\
131 \\
97 \\
139 \\
218 \\
125 \\
123 \\
127 \\
169\end{array}$ & $\begin{array}{r}164 \\
119 \\
127 \\
140 \\
136 \\
94 \\
159 \\
296 \\
134 \\
133 \\
134 \\
188\end{array}$ & $\begin{array}{l}170 \\
153 \\
146 \\
155 \\
156 \\
107 \\
176 \\
351 \\
174 \\
161 \\
159 \\
220\end{array}$ & $\begin{array}{l}183 \\
175 \\
173 \\
190 \\
183 \\
106 \\
246 \\
458 \\
193 \\
187 \\
185 \\
275\end{array}$ \\
\hline
\end{tabular}

Fuente: Elaboración propia a partir de los Censos Oficiales de Población.

Entre 1860 y 1887 la población de la capital malacitana creció a una tasa media anual muy importante, concretamente del 1,26 por 100 . Esta tasa superó ligeramente a la media nacional, 1,14 por 100 , y casi dobló a la registrada en Andalucía, 0,68 por 100. Málaga fue la segunda capital andaluza, tras Huelva, donde la población experimentó un mayor aumento.

Si observamos los cuadros 14 y 21 podemos comprobar que entre 1877 y 1887 el crecimiento poblacional a nivel provincial, 19.055 habitantes, coincide prácticamente con el registrado en la capital, 18.923. Esto probablemente obedeció a que tras la irrupción de la filoxera, y el consiguiente arrasamiento de los viñedos, se produjo un desplazamiento de población desde las zonas rurales a la capital en busca de trabajo.

El periodo más crítico fue el comprendido entre 1887 y 1897 . En esos diez años la población descendió en un 6,4 por 100 . Este porcentaje coincide con la media provincial, lo que es una prueba fehaciente de que la dramática crisis económica que vivió la provincia afectó tanto al mundo rural como al de la capital, al menos desde un punto de vista poblacional. Málaga fue la única capital andaluza donde se produjo una disminuición de la población.

Tal y como puede observarse en el cuadro 22, Málaga fue una ciudad poblacionalmente dinámica hasta mediados de la década de los años ochenta. Desde entonces se adaptó a la pauta de las capitales andaluzas, claramente retardadas respecto al proceso urbanizador de las capitales españolas. 
En las dos primeras décadas del presente siglo el ritmo de crecimiento fue lento e inferior a las medias nacional y regional. Baste decir que en el año 1910 la capital seguía contando con una población inferior a la existente en 1887. Fue en el período 1920-1930 cuando, al amparo del inicio de la revitalización económica, se consiguió un importante crecimiento poblacional. En esta década la población creció un 22 por 100 , porcentaje casi similar al experimentado entre 1877 y 1920 . En la tercera década del presente siglo la población aumentó a una tasa media anual del 2,01 por 100 , tasa ligeramente inferior a la registrada a nivel nacional, 2,21 por 100, y muy superior a la media de las capitales andaluzas, 1,53 por 100 .

Entre 1860 y 1030 la capital de la provincia fue, tal y como dijimos anteriormente, el municipio con un crecimiento demográfico más destacado. Teniendo en cuenta que la industria textil y siderúrgica atravesaron por una crítica situación, es probable que en el mayor crecimiento poblacional experimentado en la capital influyera la existencia de otras industrias menores, conservas, elaboración de pastas para sopa, entre otras, que de modo integrado pudieron demandar trabajo ${ }^{33}$.

\subsection{Hoya de Málaga}

Gracias a la suavidad de su clima y a su rico suelo aluvial, la Hoya es una zona caracterizada por la existencia de fértiles vegas. Como consecuencia de ello, esta comarca ha presentado tradicionalmente una concentración poblacional relativamente alta.

Entre 1860 y 1930 la población de la Hoya creció un 47 por 100, segundo porcentaje más alto de toda la provincia. Este crecimiento se produjo principalmente entre los años 1860-1887 y 1910-1930. El decenio 1887 1897 fue muy grave para la comarca, ya que la población se redujo en un 9,5 por 100 . Junto con la Axarquía, la Hoya fue la comarca donde el descenso poblacional revistió una mayor gravedad. Además, estas dos comarcas fueron las que experimentaron un menor crecimiento de población en la primera década de la presente centuria. Todo ello obedeció probablemente a que ambas comarcas eran las áreas donde el cultivo del viñedo gozaba de una mayor importancia y, por lo tanto, fueron las más afectadas como consecuencia de la filoxera. La gran crisis vitivinícola, rematada con la plaga filoxérica, ejerció sin duda alguna una influencia decisiva sobre la evolución de la población.

\footnotetext{
${ }^{33}$ Nadal (1987), pp. 23-61.
} 


\section{CUADRO 23}

Evolución población. Comarca: Hoya de Málaga

\begin{tabular}{|c|c|c|c|c|c|}
\hline & (1) & (2) & (3) & (4) & (5) \\
\hline $\begin{array}{llllll}1860 & \ldots & \ldots & \ldots & \ldots & \ldots \\
1877 & \ldots & \ldots & \ldots & \ldots & \ldots \\
1887 & \ldots & \ldots & \ldots & \ldots & \ldots \\
1897 & \ldots & \ldots & \ldots & \ldots & \ldots \\
1900 & \ldots & \ldots & \ldots & \ldots & \ldots \\
1910 & \ldots & \ldots & \ldots & \ldots & \ldots \\
1920 & \ldots & \ldots & \ldots & \ldots & \ldots \\
1930 & \ldots & \ldots & \ldots & \ldots & \ldots\end{array}$ & $\begin{array}{l}40.556 \\
47.197 \\
50.698 \\
45.842 \\
50.925 \\
51.581 \\
55.272 \\
59.688\end{array}$ & $\begin{array}{r}6 . \overline{6} \\
3.501 \\
-4.856 \\
5.083 \\
656 \\
3.691 \\
4.416\end{array}$ & $\begin{array}{r}\overline{0,89} \\
0,71 \\
-1,00 \\
3,50 \\
0,13 \\
0,69 \\
0,77\end{array}$ & $\begin{array}{l}52 \\
60 \\
65 \\
58 \\
65 \\
66 \\
70 \\
76\end{array}$ & $\begin{array}{l}100 \\
116 \\
125 \\
113 \\
125 \\
127 \\
136 \\
147\end{array}$ \\
\hline
\end{tabular}

(1) Población total.

(2) Crecimiento período intercensal.

(3) Tasa media anual de crecimiento intercensal (\%).

(4) Densidad.

(5) Números indices.

Fuente: Elaboración propia a partir de los Censos Oficiales de Población.

\subsection{Depresión de Antequera}

La Depresión de Antequera experimentó entre 1860 y 1930 un crecimiento poblacional del 37 por 100 , idéntico al registrado en el total de la provincia. Esta región es una prolongación del mundo físico y humano de las campiñas béticas. Es una zona caracterizada por la presencia de grandes explotaciones y en donde el cultivo de secano desempeña un papel preponderante, especialmente el cereal y el olivar.

Como se observa en el cuadro 24, la población de la Depresión aumentó a un ritmo sostenido entre 1860 y 1930 . Fue la comarca que en los años críticos de 1887 a 1897 tuvo una menor pérdida poblacional. Era una región donde el viñedo prácticamente no existía, por lo que la influencia negativa de la filoxera apenas se dejó notar, y donde los cultivos más importantes eran el cereal y el olivar. Aunque estos últimos atravesaron también por sendas crisis, éstas no revistieron en modo alguno la gravedad que alcanzó la del viñedo. Por otro lado, era la comarca con mayor número de grandes explotaciones. Esto quiere decir que los propietarios estaban en condiciones de hacer frente a las situaciones críticas con mayores posibilidades de éxito que los minifundistas de la Axarquía, por ejemplo. 


\section{CUADRO 24}

Evolución población. Comarca: Depresión Antequera

\begin{tabular}{|c|c|c|c|c|c|}
\hline & (1) & (2) & (3) & (4) & (5) \\
\hline $\begin{array}{llllll}1860 & \ldots & \ldots & \ldots & \ldots & \ldots \\
1877 & \ldots & \ldots & \ldots & \ldots & \ldots \\
1887 & \ldots & \ldots & \ldots & \ldots & \ldots \\
1897 & \ldots & \ldots & \ldots & \ldots & \ldots \\
1900 & \ldots & \ldots & \ldots & \ldots & \ldots \\
1910 & \ldots & \ldots & \ldots & \ldots & \ldots \\
1920 & \ldots & \ldots & \ldots & \ldots & \ldots \\
1930 & \ldots & \ldots & \ldots & \ldots & \ldots \\
\end{array}$ & $\begin{array}{r}86.434 \\
92.636 \\
97.552 \\
93.818 \\
104.386 \\
106.370 \\
110.611 \\
118.971\end{array}$ & $\begin{array}{r}\overline{6.202} \\
4.916 \\
-3.734 \\
10.568 \\
1.984 \\
4.241 \\
8.360\end{array}$ & $\begin{array}{r}\overline{0,41} \\
0,52 \\
-0,39 \\
3,55 \\
0,19 \\
0,39 \\
0,73\end{array}$ & $\begin{array}{l}38 \\
40 \\
43 \\
41 \\
46 \\
46 \\
48 \\
52\end{array}$ & $\begin{array}{l}100 \\
107 \\
113 \\
108 \\
120 \\
123 \\
128 \\
137\end{array}$ \\
\hline
\end{tabular}

(1) Población total.

(2) Crecimiento período intercensal.

(3) Tasa media anual de crecimiento intercensal (\%).

(4) Densidad.

(5) Números indices.

Fuente: Elaboración propia a partir de los Censos Oficiales de Población.

\subsection{Serrania de Ronda}

La Serranía de Ronda es una zona donde predominan principalmente las áreas montañosas. Es, en líneas generales, un medio físico hostil que hace improductivo un porcentaje muy elevado de los terrenos. Prácticamente toda la superficie cultivada es de secano y en él los cereales y olivares ocupan un lugar preponderante. Por lo que respecta a la distribución de la propiedad de la tierra podemos decir que junto a latifundios cerealistas en la llamada Altiplanicie de Ronda, coexisten minifundios atomizados en la Serranía propiamente dicha. Todos estos condicionantes no han favorecido en modo alguno el poblamiento de la región.

Entre 1860 y 1930 fue la segunda comarca con menor crecimiento poblacional, apenas un 19 por 100. Los años comprendidos entre 1877 y 1900 fueron muy graves desde un punto de vista demográfico, ya que la población se redujo en un 9,3 por 100 . En la primera década del presente siglo se inició la recuperación de la población, pero en 1910 todavía no se había logrado superar el número de habitantes existentes en 1877. Es evidente, pues, que gran parte de los pequeños propietarios de la Serranía, que eran precisamente mayoría, se vieron obligados a emigrar ante los efectos de la crisis agropecuaria finisecular y la poca ayuda que un medio físico poco apto para el desarrollo agrario podía aportarles. 


\section{CUADRO 25}

Evolución población. Comarca: Serrania de Ronda

\begin{tabular}{|c|c|c|c|c|c|}
\hline & (1) & (2) & (3) & (4) & (5) \\
\hline $\begin{array}{llllll}1860 & \ldots & \ldots & \ldots & & \\
1877 & \ldots & \ldots & \ldots & \ldots & \ldots \\
1887 & \ldots & \ldots & \ldots & \ldots & \ldots \\
1897 & \ldots & \ldots & \ldots & \ldots & \ldots \\
1800 & \ldots & \ldots & \ldots & \ldots & \ldots \\
1910 & \ldots & \ldots & \ldots & \ldots & \ldots \\
1920 & \ldots & \ldots & \ldots & \ldots & \ldots \\
1930 & \ldots & \ldots & \ldots & \ldots & \ldots \\
19 & \ldots & \ldots\end{array}$ & $\begin{array}{r}84.444 \\
93.098 \\
91.993 \\
87.057 \\
84.453 \\
88.377 \\
95.956 \\
100.193\end{array}$ & $\begin{array}{r}\mathbf{8 . 6 5 4} \\
-1.105 \\
-4.936 \\
-2.604 \\
3.924 \\
7.579 \\
4.237\end{array}$ & $\begin{array}{r}-\overline{0,57} \\
-0,12 \\
-0,55 \\
-1,01 \\
0,45 \\
0,82 \\
0,43\end{array}$ & $\begin{array}{l}38 \\
41 \\
41 \\
39 \\
38 \\
39 \\
43 \\
45\end{array}$ & $\begin{array}{l}100 \\
110 \\
109 \\
103 \\
100 \\
105 \\
114 \\
119\end{array}$ \\
\hline
\end{tabular}

(1) Población total.

(2) Crecimiento período intercensal.

(3) Tasa media anual de crecimiento intercensal (\%).

(4) Densidad.

(5) Números indices.

Fuente: Elaboración propia a partir de los Censos Oficiales de Población.

\subsection{Axarquía}

La Axarquía es una región caracterizada por una excesiva parcelación de la tierra, donde el cultivo del viñedo ha gozado tradicionalmente de gran importancia y con una presión demográfica históricamente muy fuerte.

\section{CUADRO 26}

Evolución población. Comarca: Axarquía

\begin{tabular}{|c|c|c|c|c|c|}
\hline & (1) & (2) & (3) & (4) & (5) \\
\hline $\begin{array}{llllll}1860 & \ldots & \ldots & \ldots & \ldots & \ldots \\
1877 & \ldots & \ldots & \ldots & \ldots & \ldots \\
1887 & \ldots & \ldots & \ldots & \ldots & \ldots \\
1897 & \ldots & \ldots & \ldots & \ldots & \ldots \\
1900 & \ldots & \ldots & \ldots & \ldots & \ldots \\
1910 & \ldots & \ldots & \ldots & \ldots & \ldots \\
1920 & \ldots & \ldots & \ldots & \ldots & \ldots \\
1930 & \ldots & \ldots & \ldots & \ldots & \ldots \\
\end{array}$ & $\begin{array}{l}66.282 \\
66.861 \\
58.084 \\
51.843 \\
54.709 \\
55.083 \\
57.538 \\
58.967\end{array}$ & $\begin{array}{r}\overline{579} \\
-8.777 \\
-6.241 \\
2.866 \\
374 \\
2.455 \\
1.429\end{array}$ & $\begin{array}{r}\overline{0,05} \\
-1,40 \\
-1,13 \\
1,79 \\
0,07 \\
0,43 \\
0,24\end{array}$ & $\begin{array}{l}87 \\
88 \\
76 \\
68 \\
72 \\
72 \\
76 \\
78\end{array}$ & $\begin{array}{r}100 \\
101 \\
87 \\
78 \\
82 \\
83 \\
87 \\
89\end{array}$ \\
\hline
\end{tabular}

(1) Población total.

(2) Crecimiento período intercensal.

(3) Tasa media anual de crecimiento intercensal (\%).

(4) Densidad.

(5) Números indices.

Fuenre: Elaboración propia a partir de los Censos Oficiales de Población. 
Fue la única comarca malagueña que entre 1860 y 1930 tuvo pérdida absoluta de población. En dicho intervalo de tiempo la población se redujo en un 11 por 100. Los años críticos fueron los comprendidos entre 1877 y 1897, período en el que el número de habitantes disminuyó en un 22,5 por 100 , a una tasa media anual del 1,26 por 100 . Con el nuevo siglo la población comenzó a crecer, pero a un ritmo muy lento. Como consecuencia de ello, en 1930 la población seguía siendo inferior a la existente en 1860.

La Axarquía fue, pues, la comarca malagueña más gravemente afectada desde un punto de vista poblacional. En esto influyó poderosamente la gran importancia que la vid desempeñaba en la zona y el carácter minifundista de los propietarios. A éstos, que vieron cómo sus pequeñas propiedades quedaron arrasadas como consecuencia de la plaga filoxérica, no les quedó otra alternativa que la emigración.

\section{A MODO DE SINTESIS}

Durante la segunda mitad del siglo xix la viticultura malagueña experimentó un proceso de grave decadencia. La filoxera desempeñó un papel fundamental en la crisis, pero no podemos considerarla como la única causante de la misma.

Antes de que se produjese la invasión filoxérica los dos productos básicos del sector venían ya atravesando por serias dificultades comerciales en los mercados internacionales. Por diversas razones, que ya comentamos en su momento, tanto el vino como la pasa sufrían una reducción en su demanda exterior. Así estaba la situación cuando en 1878 irrumpió la plaga en Málaga. La consiguiente caída de la producción como consecuencia de la destrucción de los viñedos vino, pues, precedida y acompañada de una pérdida de mercado. Ello contribuyó a agravar la situación, ya que los productores no pudieron compensar el descenso de la producción con una subida de los precios. Esto supuso la ruina para gran parte del campesinado.

Los intentos de replantación llevados a cabo en la provincia de Málaga no consiguieron el éxito apetecido. La mayoría de los viticultores malagueños eran pequeños propietarios que no disponían de los recursos necesarios para hacer frente a los elevados costes inherentes a la replantación. Además, los capitalistas no estaban dispuestos a prestarles dinero para la repoblación, ya que los principales mercados donde hubiera podido ir destinada la producción estaban prácticamente perdidos.

En esas condiciones de escasez de recursos, falta de préstamos y pérdida de mercado era lógico que la replantación se saldara con un fracaso. Prueba 
de ello es que en 1930 sólo se había repoblado el 29 por 100 del viñedo existente al inicio de la invasión filoxérica.

La filoxera no fue, pues, la única causa de la decadencia de la viticultura malagueña. Se limitó, eso sí, a dar el golpe de gracia a un sector ya decadente cuyos principales productos habían dejado de interesar en los mercados extranjeros, donde no había recursos y donde la usura era una práctica común a la hora de realizar préstamos.

La crisis evidentemente no afectó a todos por igual. Aquellos que disponían de medios pudieron, con mayor o menor éxito, salir a flote. Sirva de ejemplo el Litoral, comarca donde se consiguió el mayor éxito relativo a la hora de la replantación. Por contra, al pequeño agricultor malagueño que vio cómo sus cultivos quedaban arrasados, que no pudo acceder a los créditos necesarios para intentar la replantación y que incluso dudó de la operatividad de replantar debido a las grandes dificultades existentes para recuperar los mercados de exportación, no le quedó otra opción que buscar en otras tierras los medios de prosperidad que no hallaba en las suyas.

Además de la agricultura, la industria y el comercio malagueño atravesaron por una difícil situación a finales del siglo pasado. Esta crisis económica repercutió muy negativamente desde un punto de vista poblacional. Entre 1860 y 1930 Málaga fue la segunda provincia andaluza con menor crecimiento poblacional y mayor pérdida de población. Todas las comarcas malagueñas se vieron afectadas, sobre todo entre 1887 y 1897 , pero lo fue de manera especial la Axarquía. Dicha comarca, con una economía articulada en torno a la vid y donde los propietarios eran dueños de pequeñas explotaciones, registró pérdida absoluta de población entre 1860 y 1930.

\section{BIBLIOGRAFIA CITADA}

CArnero, T. (1980): Expansión viticola y atraso agrario, 1870-1900, Madrid.

Comisión Central. de Evaluación y Catastro (1898): Cartillas evaluatorias de la riqueza rústica y pecuaria, Málaga, Archivo de la Delegación de Hacienda.

Dirección General DE Adunnas (1857-1920a): Estadísticas generales del comercio de cabotaje en España, Madrid.

- (1857-1920 b): Estadísticas generales del comercio exterior de España, Madrid.

Dirección General de Estadística (1922-1929): Censo de la población de España, según el empadronamiento becbo en la Peninsula $e$ Islas adyacentes en 31 de diciembre de 1920, Madrid.

- (1923 a): Estadistica de pasajeros por mar, 1919, Madrid.

- (1923 b): Movimiento de la Población de España. Año 1918, Madrid. 
Dirección General del Instituto Geográfico, Catastral y de Estadística (1932): Censo de la población de España, según el empadronamiento becho en la peninsula e islas adyacentes y posesiones del Norte y Costa Occidental de Africa, en 31 de diciembre de 1930, Madrid.

- (1932-1934): Movimiento natural de la Población de España. Años 1927, 1928, 1929 y 1930, Madrid, 2 vols.

Dirección General del Instituto Geográfico y Estadístico (1883-1884): Censo de la población de España, según el empadronamiento becho en 31 de diciembre de 1877 por la..., Madrid, 2 vols.

- (1888): Reseña Geográfica y Estadística de España, Madrid.

- (1891): Estadística de la Emigración e Inmigración de España, 1882-1890, Madrid.

- (1891-1892): Censo de la población de España, según el empadronamiento becho en 31 de diciembre de 1887 por la..., Madrid, 2 vols.

- (1895-1919): Movimiento de la población de España. Años 1886-1892 y 1900 al 1917, Madrid, 21 vols.

- (1898): Estadística de la Emigración e Inmigración de España, 1891-1895, Madrid.

- (1899): Resultados provisionales del Censo de la población de España, según el empadronamiento becho en la Península e Islas adyacentes en 31 de diciembre de 1897, por la..., Madrid.

- (1902-1907): Censo de la población de España, según el empadronamiento becho en la Peninsula e Islas adyacentes en 31 de diciembre de 1900, Madrid, 3 vols.

- (1903 a): Estadística de la Emigración e Inmigración de España, 1896-1900, Madrid.

- (1903 b): Estadística de la Emigración e Inmigración de España, 1901 y 1902, Madrid.

- (1907): Estadística de la Emigración e Inmigración de España, 1903-1906, Madrid.

- (1910): Estadistica de la Emigración e Inmigración de España, 1907 y 1908, Madrid.

- (1912): Estadistica de la Emigración e Inmigración de España, 1909, 1910 y 1911, Madrid.

- (1913-1919): Censo de la población de España, según el empadronamiento becho en la Peninsula e Islas adyacentes, en 31 de diciembre de 1910, Madrid, 4 vols.

- (1914): Estadistica de pasajeros por mar, 1912 y 1913, Madrid.

- (1916): Estadistica de pasajeros por mar, 1914, Madrid.

- (1917 a): Estadistica de pasajeros por mar, 1915, Madrid.

- (1917 b): Estadística de pasajeros por mar, 1916, Madrid.

- (1922): Estadistica de pasajeros por mar, 1917 y 1918, Madrid.

Gil IBX̄̃̃zz, S. (1979): La población activa en España, 1860-1930, Madrid.

Guillén Robles, F. (1874): Historia de Málaga y su provincia, Málaga.

Guisado, J. M. (1983): «Crisis agraria e invasión filoxérica en la España del siglo XIX», Revista de Historia EconómiCa, núm. 2, pp. 165-184.

Información vinícola (1884), legajos 79 a 89, Archivo del Ministerio de Agricultura.

Instituto Geográfico y Estadístico (1877): Movimiento de la Población de España en el decenio de 1861-1870, por el..., Madrid.

Jefatura del Servicio General de Estadística (1929): Movimiento de la Población de España. Años 1924-1925-1926, Madrid.

Jefatura Superior de Estadística (1924): Estadística de pasajeros por mar, 1920-1922, Madrid.

- (1924-1926): Movimiento de la Población de España. Años 1919-1920 y 1921-1923, Madrid.

Jiménez Blanco, J. I. (1984): La producción agraria de Andalucía Oriental, 1874-1914, Madrid.

Junta General de Estadfstica (1863 a): Censo de la población de España, según el recuento verificado en 25 de diciembre de 1860 por la..., Madrid.

- (1863 b): Memoria sobre el Movimiento de la Población de España en los años 1858, 1859,1860 y 1861, publicada por la..., Madrid.

La Crisis Agricola y Pecuaria (1887-1889), Madrid.

LAсомва, J. A. (1980): «La filoxera en Málaga», Agricultura y Sociedad, núm. 16, pp. 323-370. 
Ministerio de Fomento, Dirección General de Agricultura, Industria y ComerCIO (1911): La invasión filoxérica en España y estado en 1909 de la reconstitución del viñedo. Resumen becho por la Junta Consultiva Agronómica de las memorias remitidas por los ingenieros del Servicio Agronómico Provincial, Madrid.

Ministerio de Fomento, Dirección General de Agricultura y Montes (1923): Avance estadístico de la producción agrícola en España. Resumen becbo por la Junta Consultiva Agronómica de las memorias de 1922 remitidas por los ingenieros del Servicio Agronómico Provincial, Madrid.

MoRILlA, J. (1974): "Vid malagueña y vid americana», Gibralfaro, núm. 26, pp. 69-89.

NADAL, J. (1987): «La industria fabril española en 1900. Una aproximación», en J. NAdal, A. Carreras y C. Sudria (comps.), La economía española en el siglo XX. Una perspectiva bistórica, Barcelona, pp. 23-61.

Pancorbo, M. (1901): Consideraciones sobre la producción y el comercio de pasas en la provincia de Málaga, Madrid.

Resumen nacional de la sección estadistica de la información vinicola (1884), legajo 69, expediente 2, Archivo del Ministerio de Agricultura.

Salas y Amat, L. (1891): La viticultura americana de la provincia de Málaga, Málaga. Servicios Agronómicos, Estadistica de producción y cultivo (1888-1900), legajos 259 a 264, Archivo del Ministerio de Agricultura.

Sobre enfermedades de la vid, legajos 13 a 26, Archivo del Ministerio de Agricultura.

Unión Mercantil (La) (1886), Málaga.

- (1887), Málaga. 